F. Child Lang. 3I (2004), 6I-99. (C) 2004 Cambridge University Press

DOI: I0.1017/So305000903005956 Printed in the United Kingdom

\title{
Semantic generality, input frequency and the acquisition of syntax*
}

\author{
ANNA L. THEAKSTON \\ University of Manchester \\ ELENA V. M. LIEVEN \\ Max Planck Institute for Evolutionary Anthropology, Leipzig \\ J ULIAN M. PINE \\ University of Nottingham \\ CAROLINE F. ROWLAND \\ University of Liverpool
}

(Received 2 September 2002. Revised 28 August 2003)

\section{A BSTRACT}

In many areas of language acquisition, researchers have suggested that semantic generality plays an important role in determining the order of acquisition of particular lexical forms. However, generality is typically confounded with the effects of input frequency and it is therefore unclear to what extent semantic generality or input frequency determines the early acquisition of particular lexical items. The present study evaluates the relative influence of semantic status and properties of the input on the acquisition of verbs and their argument structures in the early speech of 9 English-speaking children from 2; 0 to 3 ; 0 . The children's early verb utterances are examined with respect to (I) the order of acquisition of particular verbs in three different constructions, (2) the syntactic diversity of use of individual verbs, (3) the relative proportional use of semantically general verbs as a function of total verb use, and (4) their grammatical accuracy. The data suggest that although measures of semantic generality correlate with various

[*] We would like to thank all the families who took part in the research reported here. This research was funded by the Economic and Social Research Council, Grant Numbers Rooo236393 and Rooo2379II. Address for correspondence: Anna L. Theakston, Department of Psychology, University of Manchester, Oxford Rd., Manchester, Mi 3 ${ }_{9} \mathrm{PL}$, United Kingdom. tel: +44(I6I) 275 2600. fax: +44 (I6I) 2752588 . e-mail: theaksto@psy.man.ac.uk 
measures of early verb use, once the effects of verb use in the input are removed, semantic generality is not a significant predictor of early verb use. The implications of these results for semantic-based theories of verb argument structure acquisition are discussed.

\section{INTRODUCTION}

Many theories of language development depend on verb learning to explain the acquisition of adultlike syntax and invoke notions of semantic generality as a potential route into syntax. The assumption shared by these theories of acquisition is that there is a small group of semantically general verbs, often referred to as 'light verbs' (e.g. go, do, make, come), that is semantically privileged in some sense (e.g. Clark, I978; Pinker, I989; Bloom, I99 I ; Goldberg, I998; Ninio, I $999 a, b)$. These verbs are thought to provide the central means by which humans are able to describe their experiences via a linguistic code and are therefore assumed by many researchers to be central to the question of how children acquire language.

One theory of verb learning that includes a role for semantically general verbs is proposed by Pinker (1989). He argues that verb meanings are composed from a small set of innately specified semantic elements. Although the meanings of some verbs correspond directly to simple combinations of these elements and map onto basic cognitive events, the meanings of many verbs contain idiosyncratic information that must be determined through linguistic experience. According to Pinker:

'Since the basic structures formed out of the simple combinations of semantic elements will be used up quickly by light verbs such as be, have, go, do, make, put, give, take, and get, the child will be forced to hypothesize additional semantic elements (manners, means, object properties, and so on) for other verbs.'

Thus, Pinker suggests that semantically general verbs map onto the simplest combinations of semantic elements and correspond to children's existing cognitive schemas. In contrast, the acquisition of more specific verbs depends on children identifying those aspects of meaning that differentiate them from the more general meanings of the light verbs.

An alternative view on the role of semantically general (or pathbreaking) verbs in the acquisition of syntax is proposed by Ninio (1999a,b). She claims that the earliest verbs children learn in a given syntactic structure are those that directly encode the meaning of that structure, and that in learning these verbs, children are learning an abstract schema that then facilitates the acquisition of a large number of verbs that encode the same underlying 
notion (e.g. transitivity or intransitivity) but in a less direct manner. With respect to the role of semantically general verbs in the acquisition of the transitive construction, she states that:

'... most of their semantics consists of some schematic notion of transitivity, with the addition of a minimal specific element ... semantic suitability, salience, and frequency is apparently ... the reason why children start transitive word combinations with these generic verbs'.

A similar argument is put forward by Goldberg (I 998) who suggests that semantically general verbs map directly onto the meanings of argument structure constructions, and are therefore semantically privileged. She claims that:

'Support for the hypothesis that the central senses of argument structure constructions designate scenes that are semantically privileged ... comes from certain language acquisition facts. In particular, verbs that lexically designate the semantics associated with argument structure constructions are learned early and used most frequently ...'

The assumption that children learn semantically general verbs early BECAUSE they encode highly general meanings is mirrored in Clark's (r 978) work on early verb use. She suggests that children use semantically general verbs in place of more specific words they have not yet acquired:

'Many uses of these verbs are replaced, as children get older, by more specific terms. ... General purpose verbs, of course, continue to be used but become proportionally less frequent as children acquire more words for specific categories of actions.'

Thus, a number of researchers from both nativist and more empiricist viewpoints make the assumption that semantically general verbs have a privileged status in acquisition. However, there are three central problems with semantics-based theories of early verb acquisition. First, there is disagreement among researchers as to precisely which verbs are thought to play a privileged role in acquisition. Second, there is a confound between semantic generality and frequency (see Forner, I979 for wh-questions; Blewitt, r 982 for size adjectives; Ninio, r $999 a$ for intransitives). Semantically general verbs tend to be very frequent in the language children hear; therefore to claim that semantic generality occupies a privileged role in the acquisition process we have to show that the semantic status of individual lexical items contributes to their early acquisition over and above the effects of input frequency. Third, although a number of theorists discuss the role of semantically general verbs in acquisition, few provide precise predictions 
that can be empirically tested. It is therefore difficult to determine what the implications of a semantics-based theory are for children's early verb use that would differentiate these theories from frequency-driven learning.

The aim of the current paper is to explore the possible role of semantic generality in early verb acquisition, and to derive predictions concerning early verb use that can be tested using empirical data. Although semantic generality is typically confounded with input frequency, in the area of verb learning, it may be possible to evaluate the relative contributions to acquisition of semantic generality and input frequency. Children typically acquire semantically general verbs early in development, but they usually also acquire more specific verbs alongside these general exemplars (Clark, I978; Tomasello, I992). Thus, it should be possible to determine whether the extent to which a verb is semantically general influences its early acquisition over and above the effects of input frequency which would be expected to affect the acquisition of both general and more specific verbs equally. Previous research has shown that specific properties of the input, namely frequency and the number of sentence frames in which individual verbs appear, predict the order of acquisition of particular verbs in children's speech (Naigles \& Hoff-Ginsberg, I 998, see also de Villiers, I 984). What is not yet clear is the extent to which the semantics of individual verbs may also affect the order in which particular verbs are acquired and used in a range of different argument structures. It is important to note that the lack of clarity with respect to the developmental implications of particular theories means that the predictions derived represent the present authors' interpretation of the theories explored.

\section{Predicting the order of acquisition of individual verbs}

One prediction derived from Clark's (1978), Bloom's (I99i), and Ninio's $(\mathrm{r} 999 a, b)$ theories is that semantically general verbs will be acquired earlier than more specific verbs. More specifically, within a given syntactic structure, the first verbs to be acquired will be semantically general and these verbs will be followed by the acquisition of more specific verbs in that structure. Clark claims that early in development, general purpose verbs are used in place of more specific verbs that have not yet been acquired, and thus semantically general verbs should be acquired early (see also Bloom, I 99 I). Ninio claims that in acquiring semantically general verbs, children learn abstract schemas that facilitate the acquisition of a large number of more specific verbs, thus semantically general verbs should be learned early. Similarly, Bloom ( I 99 I) claims that children's early verb categories are semantically-based and initially consist mainly of 'the highly frequent, all purpose pro-verbs', and that only once these categories are acquired can children begin to learn a wider

range of semantically specific verbs. However, if the early acquisition of 
semantically general verbs allows children to gain the knowledge necessary to acquire more specific verbs, and reflects their semantic status rather than their frequency, semantic generality should predict the order of acquisition of verbs over and above the effects of verb frequency.

If children began to produce a range of different syntactic structures at the beginning of multiword speech, we would expect to find an overall effect of semantic generality on the order of acquisition of verbs, as the generic verbs that allow children to acquire each different syntactic structure should be acquired at the same time. However, if children initially produce only a small number of structures, it is possible that they will not acquire semantically general verbs whose meanings are consistent with other structures until later in development. This might mean that children have begun to produce more specific verbs in some structures before they begin to produce semantically general verbs in other later-emerging structures, and therefore that the effects of semantic generality may be masked in an overall analysis of the order of acquisition of individual verbs. In addition to an overall analysis of verb acquisition, we therefore investigate the role of semantic generality and input frequency on the age of acquisition of individual verbs in specific syntactic structures. If the early acquisition of semantically general verbs allows children to gain the more abstract knowledge of a given structure necessary to acquire more specific verbs in that structure, semantic generality should predict the order of acquisition of verbs within a given structure over and above the effects of input frequency.

\section{Predicting the acquisition of verb argument structure}

In the adult language, semantically general verbs can be used in a range of different structures and/or with a range of different complements, whereas more specific verbs are restricted in their syntactic behaviour (Hollebrandse $\&$ van Hout, I 998). One prediction derived from Ninio's ( I 999 $a, b$ ) and Pinker's ( 1989 ) theories is that at the earliest stages of development, semantically general verbs will appear in a more diverse set of syntactic frames than more specific verbs. In Ninio's theory, children acquire an abstract knowledge of a given syntactic structure through the first semantically general verbs acquired in that structure, which then enables them to acquire verbs in that structure with more specific meanings. Semantically general verbs are likely to be among the earliest verbs acquired in a number of different structures resulting in greater syntactic diversity (e.g. Ninio ( $1999 b$ ) reports that the verb 'want' is acquired early in both SVO and VO structures). In Pinker's theory, children establish the phrase structure rules for the target language by applying innate linking rules once a verb's semantic structure has been identified. These rules can then be used to determine the possible meaning of new verbs used in that structure. Semantically general verbs have transparent meanings, and will 
therefore be mapped onto children's syntactic structures quickly once acquired. In contrast, early acquired verbs with specific meanings are likely to be acquired in a rote-learned manner as a label for a particular event, without a full understanding of the semantics-syntax correspondences for that verb. This is likely to lead to greater productivity in the use of semantically general verbs in contrast with more specific rote-learned verbs resulting in greater syntactic diversity. This prediction is supported by the findings that light verbs are the first to appear in the earliest acquired Wh-question structures (Bloom, Merkin \& Wootten, I982), and that earlier learnt verbs are more likely than newly acquired verbs to appear in complex sentence structures, assuming that light verbs are acquired early (Bloom, Miller \& Hood, I 975).

Clark's (1978) theory suggests that the extent to which a verb is semantically general should predict its syntactic diversity over and above the effects of syntactic diversity in the input, because children are initially expected to use semantically general verbs where adults would use more specific verbs (see also Hollebrandse \& van Hout, I998). Although adults may modify their speech when talking to children and use semantically general verbs in place of more specific verbs that children may not understand (thus increasing the number of frames in which these verbs appear), they would not be expected to produce the argument structure errors with these verbs that are observed in early child speech (Hollebrandse \& van Hout, I 998).

\section{Predicting the relative use of individual verbs in children's early speech}

One prediction derived from Clark's ( I978) theory is that the proportional use of semantically general verbs in children's speech will be higher than in adult speech. While adults who know a wide range of semantically specific verbs should use these verbs, children are expected to use semantically general verbs to express concepts for which they have not yet acquired more specific verbs. Children's proportional use of semantically general verbs should decrease over the course of development as more specific verbs are acquired. However, it is possible that when mothers talk to children, they use semantically general verbs in place of more specific verbs to increase the chances that children will understand them. This would make it difficult to determine whether children's high proportional use of semantically general verbs reflected their semantic generality, or their use in the input. To claim that the semantic status of individual verbs leads children to generalize use of semantically general verbs where more specific verbs would normally be used in adult speech, it is necessary to show that (a) the proportional use of semantically general verbs in mothers' speech is not noticeably higher than in adult-adult speech, and (b) the proportional use of semantically general verbs in children's speech is significantly higher than in adult-adult speech. A similarly high proportional use of semantically general verbs in children's 
speech as in adult-adult speech, where adults would not be expected to adapt their speech to aid comprehension, would suggest that children's use of these verbs is more likely to be determined by frequent use in the input rather than by the semantic status of the verbs involved.

\section{Predicting the syntactic accuracy of children's early verb utterances}

Both Ninio's and Pinker's theories suggest that children produce the argument structures associated with individual verbs by applying abstract schemas or rules that support the production of a given structure (e.g. a transitive schema, or innate phrase structure rules). These rules or schemas are assumed to be initially accessed or acquired via the learning of semantically general verbs that map transparently onto the semantic-syntactic correspondences encoded by innate linking rules, or whose semantics most directly encode a given combinatorial pattern (e.g. transitivity). More specific verbs carry additional semantic content. Therefore, to apply the correct linking rules, or to transfer abstract knowledge of a given syntactic frame, children must dissect the grammatically relevant semantic content shared with a semantically general verb from the overall semantics of the verb. One prediction that can be derived from these theories is that children will make more errors in their production of subject and direct object arguments in obligatory contexts with more specific than with semantically general verbs. This is because the processing load associated with accessing the underlying rules or schemas is likely to be greater for more specific verbs that carry additional meaning than for general verbs that directly encode the meaning of the abstract schema concerned. There is some evidence in support of this prediction. First, Bloom, Miller \& Hood (I975) report that children are more likely to omit obligatory arguments with new verbs than with familiar verbs because the processing demands associated with new verbs are higher and the production of obligatory arguments less automatized. Second, Ninio \& Keren-Portnoy (2002) claim that prior to a rapid increase in verb learning, children make errors in their use of semantically general verbs that is attributed to a period of 'intense learning and practice' of the relevant syntactic structures that 'delays the acquisition of new verbs in the same syntactic patterns'. This suggests that before children can transfer their knowledge of a given structure to new verbs, they must learn to produce early acquired semantically general verbs correctly, whereas later learned verbs will be less practised and may be more susceptible to errors.

To summarize, the predictions derived from a range of theories of early verb learning that incorporate a privileged role for semantically general verbs are as follows:

I. Semantically general verbs will be acquired earlier than more specific verbs, at least within specific syntactic structures. 
2. Semantically general verbs will be used in a wider range of structures than more specific verbs.

3. Semantically general verbs will account for a greater proportion of children's verb utterances than adult verb utterances.

4. Semantically general verbs will show higher levels of provision of subject and direct object arguments in obligatory contexts than more specific verbs.

The alternative position is that input frequency predicts children's early verb use to a much greater extent than does the semantic status of individual verbs. Thus, if input frequency is found to predict children's early verb use but the predictions outlined above that differentiate between frequency-based and semantic-based explanations of verb acquisition are not supported, this would suggest that it is the frequency and distributional properties of individual verbs in the input much more than the semantic status of verbs that influences early verb learning.

\section{Which verbs are semantically general?}

In the literature, 'light' verbs have been categorized on the basis of three related although logically independent variables: frequency, semantic generality, and their tendency to grammaticalize cross-linguistically. However, there is a lack of consensus as to exactly how the semantically general verbs that are thought to have a privileged role in acquisition should be defined. Clark ( I 978) describes general purpose verbs (do, go, make, put, get, take) as highly general, frequent, and dependent on context for their interpretation, but she does not label the highly frequent verb sit as a general purpose verb illustrating that high frequency alone may be insufficient to determine a verb's semantic status. In contrast, Ninio (1999 $a, b)$ defines what she calls prototypical verbs in terms of their tendency to appear as grammaticalizing verbs cross-linguistically, i.e. lexical verbs which over time become grammaticalized to auxiliaries or aspect markers. She also notes that these verbs tend to be frequent, following Traugott \& Heine (I99I) who state that frequency is a necessary condition for grammaticalization (see Appendix I, column 3 for a full list of verbs Ninio lists as semantically general). From Ninio's perspective, the extent to which a verb is semantically general is reflected in the extent to which that verb is grammaticalized across languages resulting in a continuum of verbs from semantically general to more specific exemplars. ${ }^{1}$

[I] It is unclear how the position of individual verbs on this continuum should be defined given that it is difficult to quantify the extent to which particular verbs undergo grammaticalization crosslinguistically. 
There is a further lack of consensus when we examine Pinker's theory. In line with others, his theory suggests that the most semantically general of verbs (do, go, make, put, get, take, give, have, come, bring) are privileged in the acquisition process. In determining the meaning of these verbs, children gain access to innately given grammatical structure and are helped to establish the semantics of more specific verbs. However, his view that transitive verbs that encode highly volitional agent-patient relations are semantically privileged contrasts directly with Ninio's ( I999 $a, b$ ) definition of semantically general verbs, namely those verbs which encode a strong inherent relationship between a verb and its object (Pinker's definition is necessary in his linking rules theory to ensure that children learn the correct mappings between semantics and syntax such that agents are encoded as sentence subjects etc.).

In addition to the lack of agreement as to which verbs are thought to be semantically general, there is also a lack of consensus concerning the structures that these verbs are assumed to map on to. To illustrate this point, compare the definitions given by Goldberg (1998) and Ninio (1999a). Both theorists view semantically general verbs as exemplifying the meaning of a specific syntactic structure, but the structures they discuss are defined in rather different terms. Ninio (r999a) differentiates VO and SVO structures, whereas Goldberg considers both of these structures to be exemplars of a single construction, the transitive. However, she differentiates between the transitive and possessive constructions in terms of their meaning ( $\mathrm{X}$ acts on $\mathrm{Y}$ vs. $\mathrm{X}$ acquires/possesses $\mathrm{Y}$ ), although both could be exemplars of Ninio's VO or SVO structures. As a result, it is unclear exactly which structures children are thought to acquire through their early use of semantically general verbs. However, it is important to note that while Goldberg argues that semantically general verbs have a privileged role in acquisition, unlike Ninio, she does not view these verbs as the necessary precursors to the acquisition of more specific verbs in a given structure. Instead, she argues that semantically general verbs provide semantic prototypes for the development of more abstract constructions. In her view, abstract constructions emerge gradually as children begin to recognize similarities in form and meaning between verbs with more specific semantics that are initially learned as independent verb islands (Tomasello, I 992). She suggests that semantically general verbs 'could act as a centre of gravity for other expressions having the same form' (Goldberg, I998).

Given the apparent lack of consensus in the literature, for the purposes of the present study, two different definitions of semantically general verbs will be adopted focusing on (I) verbs that at least two of the above theorists define as semantically general, and (2) grammaticalizing verbs (see Appendix I for a full list and semantic categorization of the verbs produced by the children), and the predictions outlined above will be tested according 
to the two categorization schemes. Scheme I includes all the verbs listed by Clark and all the verbs listed by Pinker as semantically general (excluding have). This scheme is therefore taken to represent these two theories. Ninio lists a large number of other verbs, in addition to the Scheme I verbs, as semantically general. Scheme 2 is taken to represent Ninio's theory. These schemes are based on the verbs listed by the various theorists as 'examples' of semantically general verbs. Therefore, it is likely that these lists are not exhaustive, and some verbs categorized as semantically specific may be regarded as semantically general by the theorists mentioned above. However, without more comprehensive categorization schemes, it is impossible to determine exactly which verbs would be regarded as semantically general according to the different theoretical perspectives beyond the verbs listed in the literature. Broadly speaking, we consider all uses of the verbs listed to be semantically general. However, as the individual analyses carried out focus on the use of semantically general and more specific verbs in particular structures, this results in a narrower definition of semantic generality with respect to individual verbs. For example, uses of the verb go as a marker of future intent (I'm going to make dinner tonight) do not enter into the analysis of the acquisition of the intransitive structure. Finally, given the lack of consensus regarding the nature of the structures children are thought to acquire, in the current study we focus on the structures outlined in Ninio's ( I $999 a, b$ ) theory of acquisition, namely the SVO, VO and intransitive structures.

The purpose of the study is to examine to what extent the semantic generality of individual English verbs influences their acquisition and early use. The aim of the analyses is to cast some light on the relation between semantic generality, the use of particular verbs in the input to which children are exposed, and the pattern of early verb acquisition. Longitudinal data from 9 English-speaking children will be examined to investigate (I) the age of acquisition of individual verbs, and (2) the children's pattern of verb use at Stage I (MLU I·०o-I·99). At Stage I, children are just beginning to produce multiword utterances including verbs and therefore, it is at this early stage in development that the effects of semantic generality on early verb use should be most evident if semantically general verbs have a privileged status in the language acquisition process.

\section{METHOD}

\section{Participants}

The children in this study were nine of twelve children who took part in a longitudinal study of early language development. In this study, we predominantly examined Stage I data. Three children did not produce any Stage I data and so were excluded from this analysis. The children were 
from middle-class families and were recruited through newspaper advertisements and local nurseries. All of the children were from monolingual English-speaking families, were first-borns and were cared for primarily by their mothers. At the beginning of the study the children ranged in age from I; I 0.7 to $2 ; 0.25$ with MLUs ranging between I. 06 and I.76 in morphemes. MLU was calculated in morphemes for each recording using the CLAN programs (MacWhinney, I995) and excluded self-repetitions, imitations, partially intelligible utterances, incomplete utterances and routines (e.g. nursery rhymes, counting). These utterances were excluded from all analyses.

\section{Procedure}

The children were audiotaped in their homes for an hour on two separate occasions in every three week period for one year. They engaged in normal everyday interaction with their mothers. The data were orthographically transcribed using the CHILDES system (MacWhinney, I995) and are available on CHILDES as the Manchester corpus (Theakston, Lieven, Pine \& Rowland, 200I). To ensure transcription accuracy, prior to the beginning of the study, two transcribers were extensively trained and agreed a detailed set of transcription and coding guidelines. Initially, a number of transcripts were independently transcribed by each of the transcribers and compared to check for accuracy. The level of agreement between the transcribers was $85 \%$. Subsequently, approximately every 20 th transcript was checked to ensure continuing levels of agreement between the transcribers.

\section{The mothers' speech corpora}

Two measures of verb frequency were calculated. First, each mother's data from the first four tapes were searched for all verbs and the total frequency of each verb calculated. Second, the frequency of use of individual verbs in $\mathrm{VO}, \mathrm{SVO}$ and intransitive structures was calculated for these data for each mother. For this measure of verb frequency, verbs were considered to be part of (I) a VO construction if they appeared with a direct object immediately following the verb regardless of any additional complexity in the sentence (i.e. questions with preposed wh-word objects were not counted, but VO combinations that occurred in structures that contained subordinate clauses, infinitival structures etc. were included), (2) a SVO construction if they appeared with a direct object immediately following the verb and a subject argument that related to the verb in question regardless of any additional complexity in the sentence, and (3) an intransitive construction if the verb was obligatorily or optionally intransitive and did not appear with a direct object, regardless of any additional complexity in the 
sentence (e.g. prepositional complements, infinitival structures, subordinate clauses). Verbs that appeared in a given utterance but were not used in any of these three constructions were excluded, for example, auxiliary-like verbs such as going + to/gonna, want +to/wanna and verbs taking sentential complements.

For all analyses, incomplete utterances, partially intelligible utterances and routines were excluded from the mothers' corpora. Ideally, the mothers' corpora would have been taken from a period of time preceding the children's corpora to rule out the possibility that similarities between mothers and children may result from the discourse context and the fact that both mothers and children were engaged in the same conversations. However, this was not possible because for this study we needed to examine the children's Stage I data, and no earlier samples of mother speech were collected. Therefore, a number of analyses were carried out to help determine whether the frequency of use of individual verbs in the mothers' speech was independent of the effects of the children's use of particular verbs. First, cross-correlations comparing the frequency of verb use in the mothers' speech on tape I and the frequency of verb use in the children's speech both within-tape (tape I) and between-tape (tape 2) were calculated (Nicole was excluded from this analysis because she produced only one verb on tape I). If the frequency of verb use in the mothers' samples was strongly influenced by their children's verb use, the correlations between each mother and her child should be higher within-tape when they were engaged in the same conversation, than between-tape when the conversations were independent. Two correlations were calculated for each dyad comparing the frequency of use of individual verbs within-tape and between-tapes. Fisher's transformations were applied to the correlation coefficients and the difference between the two values for each dyad tested using Williams' $t$-test. For five of the dyads, there was no difference between the correlation coefficients within or between tapes (non-significant $t$ values ranged from $0 \cdot$ I 0 to $\mathrm{I} \cdot 37, d f$ values ranged from 67 to ro6 based on the number of verbs produced by each dyad), whilst for three dyads, the correlation between the mothers' verb frequency on tape $I$ and the children's verb frequency on tape 2, i.e. from independent conversations, was significantly higher than the corresponding correlation between the mothers' verb frequency on tape I and verb frequency in the children's speech on tape I, i.e. from shared conversations (Anne $t=3 \cdot 66, d f=85$, $p<0.0 \mathrm{I}$; Dominic $t=2 . \mathrm{I} 9, d f=6 \mathrm{I}, p<0.05$; Liz $t=2.86, d f=8 \mathrm{I}, p<0.0 \mathrm{I})$. Second, pairwise correlations were calculated between the mothers for the frequency of use of all the verbs produced by any of the mothers. The frequency of use of these verbs in each mother's data was correlated with the frequency of use in the data from each of the other eight mothers resulting in a total of 36 correlations. All the correlations were above $0 \cdot 80$, 
$p<0.0 \mathrm{I}$, suggesting that frequency of verb use is consistent across mothers. Finally, correlations were calculated between the frequency of the verbs used by individual mothers on the first and last four tapes (the beginning and end of the year period) to determine whether frequency of verb use remained consistent over time. All 9 of the correlations were above 0.90 , $p<0.0 \mathrm{I}$, suggesting that the mothers were consistent in their use of verbs over time. Thus, although any observed similarities in verb use between the mothers and children might reflect discourse factors, these analyses suggest that participation in the same conversations is unlikely to be the only important factor underlying similarities in verb use within dyads.

\section{The children's speech corpora}

To establish the overall age of acquisition of individual verbs, each child's data from the whole year were searched for the verbs found in their mothers' speech sample and the age of acquisition calculated in days according to the date of the recording when a given verb first appeared in the child's speech. This procedure is based on analyses conducted by Rowland (2000) who found that the order of acquisition of wh-words and auxiliaries was similar when a first use and third use criterion for acquisition was used. This suggests that the first use of individual lexical items in children's early speech is representative of their order of acquisition when measured using more stringent criteria (see also Stromswold, I988). As the children did not acquire all of the verbs found in their mothers' data, verbs not acquired by each child were allocated an age of acquisition seven days later than the date of the final recording to provide a rough indication of their age of acquisition.

To determine the age of acquisition of individual verbs in the VO, SVO and intransitive structures, each child's data for the whole year were searched for the verbs used by their mothers in those structures. Following Ninio $(1999 a, b)$, only utterances containing two or more words were included in the analyses. The age of acquisition of verbs in each structure was calculated in days according to the first use of a given verb in a given structure. This means that a given verb could have very different ages of acquisition in different syntactic structures (e.g. read can be used in all three structures, but each may first be produced at different stages in development).

For analyses relating to the children's early verb use, each child's Stage I data were searched for all utterances including a verb (including only instances that were clearly main verbs rather than auxiliaries). The copula was excluded because it is difficult to categorize in terms of its semantic status, and though frequent, it appears in only a very small number of sentence frames. 


\section{Verb categorization}

For each analysis, the verbs were categorized according to their semantic status. For the first categorization, only those verbs defined as semantically general in at least two of the above studies (Clark, I978; Pinker, I989; Ninio, I $999 a, b)$ were coded as 'light' and assigned a value of one for the purposes of statistical analysis. All other verbs were coded as 'non-light' and assigned a value of zero for the purposes of statistical analysis. For the second categorization, those verbs listed as the most common verbs to undergo grammaticalization cross-linguistically by Ninio (I999 $a, b$ ) were coded as 'light' and assigned a value of two for the purposes of statistical analysis (see also Foley \& Olson, I 985 ; Bybee, Perkins \& Pagliuca, I 994). Those verbs listed by Ninio as verbs that less frequently undergo grammaticalization were coded as 'part-light' and assigned a value of one for the purposes of statistical analysis. All remaining verbs were coded as 'nonlight' and assigned a value of zero for the purposes of statistical analysis.

\section{Syntactic frames}

The children's verb utterances from Stage I, and their mothers' verb utterances were coded according to syntactic frame for each verb that appeared in a particular utterance and the number of different frames produced with each verb in each child's speech and each mother's speech calculated. The frames adopted were couched in terms of formal syntactic categories but there is no implication that the children were operating with such abstract knowledge. For declarative utterances, the frames were defined in terms of the presence or absence of subject arguments, direct object arguments, adverbial complements, prepositional phrase complements, sentential complements, resultative complements and gerund complements (e.g. $\mathrm{S}+\mathrm{V}+\mathrm{O}, \mathrm{S}+\mathrm{V}, \mathrm{V}+\mathrm{PP}$ ). Thus, the phrases put on there, belongs to him, and eaten by the $\mathrm{dog}$, would all be coded as V+PP. Each different combination of these arguments constituted a distinct argument structure frame. Tag questions were coded by the structure of the matrix clause. The following were coded as separate categories: declaratives containing negation; Wh-questions; auxiliary questions; rote utterances (where the word order is reversed with limited productivity, e.g., there it goes, here it comes); verbs that appeared as the complement of another verb. Whilst the declarative frames encode all the basic combinations of syntactic elements, these categories each represent some kind of syntactic operation that could apply to any of the basic frames. ${ }^{2}$ In addition, it was necessary to

[2] There were no verbs that only appeared in a range of structures in, for example, Wh-questions rather than in declaratives. Therefore this method of categorization accurately captures the range of structures used. 
distinguish, in the children's speech, between complete prepositional phrase complements (e.g. go in the sky) and noun phrase complements where a preposition had been omitted (e.g. going shops). A total of 35 frames were required to categorize the children's utterances and a total of $5^{6}$ frames were required to categorize the mothers' utterances. To establish whether the number of syntactic frames produced with individual verbs was similar to that reported in other studies, Pearson's correlations were computed to compare the number of verb frames produced with individual verbs in each mother's data with the number of frames produced with those verbs in a combined sample of $\mathbf{5 7}$ mothers' speech reported in Naigles \& HoffGinsberg (1998). For the 25 verbs where comparisons could be made, the correlations for all 9 mothers were above $0.73, p<0.0 \mathrm{I}$ showing that the mothers in both studies were similar in the relative number of verb frames used with individual verbs.

\section{Utterance grammaticality}

The children's Stage I utterances were coded according to their grammaticality with respect to the provision of subject and direct object arguments in obligatory contexts. To explore the children's use of subject arguments, all the verbs produced by individual children were examined and the rate of subject provision for each verb calculated. In utterances where there was no subject argument, only those utterances where the particular verb or verb form required a subject were automatically coded as having omitted subject arguments (e.g. verbs that could not be used as imperatives, or inflected verb forms). In cases where the utterance could have been an imperative, the original transcripts were examined for linguistic context. Only when the contextual information indicated that the utterance was highly unlikely to be an imperative was the utterance counted as having an omitted subject argument. To explore the children's use of direct object arguments, only those transitive verbs where the omission of a direct object could be clearly identified were examined and the rate of direct object provision for each verb produced by each child calculated (Appendix I shows the complete list of verbs examined for direct object provision).

\section{RESULTS}

Table I shows summary data for the children's corpora and the input samples used in these analyses. Table 2 shows summary data for the children's Stage I corpora. Appendix I lists the verbs produced by the children and shows the semantic classification of each verb for both semantic categorization schemes. 
TABLE I. Summary of children's corpora (the Manchester corpus) and the input samples

\begin{tabular}{|c|c|c|c|c|c|c|c|c|c|}
\hline Child & Age range & $\begin{array}{l}\text { No. child } \\
\text { utterances }\end{array}$ & $\begin{array}{l}\text { Mean age of } \\
\text { verb acquisition } \\
\text { in days (S.D.) }\end{array}$ & $\begin{array}{l}\text { No. verb } \\
\text { types in } \\
\text { input } \\
\text { sample }\end{array}$ & $\begin{array}{l}\text { No. light } \\
\text { verb types } \\
\text { in input } \\
(\text { scheme } \mathrm{I})\end{array}$ & $\begin{array}{l}\text { No. light } \\
\text { verb types } \\
\text { in input } \\
\text { (scheme } 2)\end{array}$ & $\begin{array}{l}\text { No. part- } \\
\text { light verb } \\
\text { types in } \\
\text { input } \\
\text { (scheme 2) }\end{array}$ & $\begin{array}{l}\text { No. verb } \\
\text { types in } \\
\text { input } \\
\text { produced } \\
\text { by child }\end{array}$ & $\begin{array}{l}\text { Mean tokens/ } \\
\text { verb in input } \\
\text { sample (S.D.) }\end{array}$ \\
\hline Anne & I ; I0.7-2;9.10 & I 5 I 46 & $772 \cdot 49($ I I 7·89) & I 43 & 9 & 20 & I 6 & 127 & I $5 \cdot 30(36 \cdot 48)$ \\
\hline Aran & I ; I I.I $2-2 ; 10.28$ & I 2973 & $879 \cdot 38($ I $46 \cdot 83)$ & 212 & 9 & I 8 & I 8 & I 44 & I $3.50(39.40)$ \\
\hline Becky & $2 ; 0.7-2 ;$ I I.I 5 & I 6489 & $870 \cdot 80(131 \cdot 36)$ & I 48 & 9 & I9 & I 4 & I I 5 & I $3.55(3 \mathrm{I} \cdot 87)$ \\
\hline Dominic & I; 10.24-2; 10.1 6 & I 449 I & $894 \cdot 32($ ( $32 \cdot 08)$ & I 38 & 9 & 20 & I 2 & 93 & I $3.01 \quad(33.45)$ \\
\hline Gail & I ; I I.27-2; I I. I 2 & I 28 I 9 & $847 \cdot 67(139 \cdot 85)$ & I 83 & 9 & I9 & I 5 & I 49 & I0.34 (23.99) \\
\hline Joel & I ; I I.I-2; IO.I I & 13670 & $850 \cdot 06($ I 2 I. 44$)$ & I 64 & 9 & 20 & I 4 & I38 & I I.06 $(29.67)$ \\
\hline $\mathrm{Liz}$ & I ; I I.9-2; I0. I 8 & I I 58 I & $865.96($ ( $39 \cdot 60)$ & I 46 & 9 & I 8 & I 5 & I08 & $10.98(27.32)$ \\
\hline Nicole & $2 ; 0.25-3 ; 0.10$ & I I 460 & $964 \cdot 3$ I $($ I 2 I $\cdot 88)$ & I 63 & 9 & 20 & I 4 & I 12 & $13.50(37.21)$ \\
\hline Ruth & I ; I I.I 5-2; I I.2 I & I 3468 & 984.06 ( I I 8.62) & I 54 & 9 & I9 & I 7 & 88 & I6.77 (38.9I) \\
\hline
\end{tabular}

TABLE 2. Stage I data for each child

\begin{tabular}{|c|c|c|c|c|c|c|c|c|c|}
\hline Child & $\begin{array}{c}\text { Total } \\
\text { no. of } \\
\text { utterances }\end{array}$ & $\begin{array}{c}\text { No. of } \\
\text { verb } \\
\text { utterances }\end{array}$ & $\begin{array}{l}\text { No. of } \\
\text { verb } \\
\text { types }\end{array}$ & $\begin{array}{l}\text { No. light } \\
\text { verb types } \\
\text { (scheme I) }\end{array}$ & $\begin{array}{l}\text { No. light } \\
\text { verb types } \\
\text { (scheme } 2 \text { ) }\end{array}$ & $\begin{array}{c}\text { No. part-light } \\
\text { verb types } \\
\text { (scheme } 2 \text { ) }\end{array}$ & $\begin{array}{l}\text { Range no. of } \\
\text { tokens/verb }\end{array}$ & $\begin{array}{l}\text { No. of } \\
\text { tapes }\end{array}$ & $\begin{array}{l}\text { MLU } \\
\text { range }\end{array}$ \\
\hline Anne & 2463 & 580 & 85 & 7 & I 5 & I I & $\mathrm{I}-85$ & 6 & $I \cdot 6 I-I \cdot 92$ \\
\hline Aran & IOIO & $26 I$ & 54 & 6 & I 3 & 9 & $\mathrm{I}-37$ & 3 & $\mathrm{I} \cdot 4 \mathrm{I}-\mathrm{I} \cdot 83$ \\
\hline Becky & 2982 & 543 & 83 & 7 & I 6 & IO & $\mathrm{I}-47$ & 8 & $\mathrm{I} \cdot 42-\mathrm{I} \cdot 97$ \\
\hline Dominic & 2843 & 409 & 49 & 7 & I 5 & IO & $\mathrm{I}-84$ & IO & $\mathrm{I} \cdot 20-\mathrm{I} \cdot 86$ \\
\hline Gail & I I I 7 & 233 & 71 & 8 & I 5 & 8 & $I-2 I$ & 3 & $\mathrm{I} \cdot 69-\mathrm{I} \cdot 88$ \\
\hline Joel & I 897 & 254 & $6_{3}$ & 7 & I 4 & 6 & $I-30$ & 8 & $\mathrm{I} \cdot 33^{-I} \cdot 87$ \\
\hline $\mathrm{Liz}$ & I 792 & 265 & 47 & 7 & I 3 & 6 & $I-46$ & 5 & $\mathrm{I} \cdot 35^{-I} \cdot 88$ \\
\hline Nicole & 4782 & 779 & $9 \mathrm{I}$ & 7 & I 6 & I 4 & $\mathrm{I}-\mathrm{IO} 4$ & I7 & $I \cdot 06-2 \cdot 3 \mathrm{I}$ \\
\hline Ruth & 3492 & 215 & I 8 & 4 & 7 & 5 & $\mathrm{I}-54$ & I I & $\mathrm{I} \cdot 34-\mathrm{I} \cdot 97$ \\
\hline
\end{tabular}


TABLE 3. Correlations between age of first use, input frequency, and two measures of semantic generality for all verbs present in individual mother's input samples

\begin{tabular}{|c|c|c|c|c|c|}
\hline \multirow[b]{2}{*}{ Child } & \multicolumn{3}{|c|}{ Age of first use and: } & \multicolumn{2}{|c|}{ Input frequency and: } \\
\hline & $\begin{array}{c}\text { Input } \\
\text { frequency }\end{array}$ & $\begin{array}{l}\text { Semantic } \\
\text { scheme I }\end{array}$ & $\begin{array}{l}\text { Semantic } \\
\text { scheme } 2\end{array}$ & $\begin{array}{l}\text { Semantic } \\
\text { scheme I }\end{array}$ & $\begin{array}{l}\text { Semantic } \\
\text { scheme } 2\end{array}$ \\
\hline Anne & $-0.5 \mathrm{I} * * *$ & -0.15 & $-0.24^{* *}$ & $0.40^{* * * *}$ & $0.52^{* * * *}$ \\
\hline Aran & $-0.60 * * *$ & $-0.2 \mathrm{I} * *$ & $-0.39 * * *$ & $0.47 * * *$ & $0.55^{* * * *}$ \\
\hline Becky & $-0.54^{* *}$ & $-0.22^{* *}$ & $-0.37^{* * * *}$ & $0.48 * * *$ & $0.56^{* * * *}$ \\
\hline Dominic & $-0.63 * * *$ & $-0.30 * * *$ & $-0.5 \mathrm{I} * * *$ & $0.50 * * *$ & $0.57^{* * * *}$ \\
\hline Gail & $-0.42^{* * * *}$ & $-0.19^{*}$ & $-0.3 I^{* *}$ & $0.44^{* * * *}$ & $0.58 * * *$ \\
\hline Joel & $-0.52^{* * *}$ & $-0.19^{*}$ & $-0.34^{* * * *}$ & $0.37 * * *$ & $0.53 * * *$ \\
\hline $\mathrm{Liz}$ & $-0.54^{* * *}$ & $-0.25^{* *}$ & $-0.42^{* * * *}$ & $0.50 * * *$ & $0.67 * * *$ \\
\hline Nicole & $-0.59^{* * * *}$ & $-0.24^{* *}$ & $-0.43^{* * * *}$ & $0.49 * * *$ & $0.60 * * *$ \\
\hline Ruth & $-0.6 \mathrm{I} * * *$ & $-0.30 * * *$ & $-0.58 * * *$ & $0.46 * * *$ & $0.59 * * *$ \\
\hline
\end{tabular}

* $p<0.05$; ** $p<0.01$; *** $p<0.001$.

\section{Input frequency and semantic generality}

All verbs used by individual mothers. First, the hypothesis that semantic generality would influence the overall age of acquisition of individual verbs was examined. Pearson's correlations were calculated to establish whether input frequency and semantic generality were related to the age of acquisition (measured in days) of individual verbs in the children's speech over the whole year (see Table 3 ). ${ }^{3}$

However, since the frequency distribution of verbs in the input was extremely skewed, log transformations were used in the analysis (see Huttenlocher, Haight, Bryk, Seltzer \& Lyons, I 99I). The correlations show that input frequency and the second measure of semantic generality were

[3] In all correlation analyses, Pearson's correlations are reported. They are appropriate for variables measured on a continuous scale (age of acquisition, verb frequency, no. of verb frames), and can also be used as a point-biserial correlation with dichotomous variables (semantic scheme one). Semantic scheme two is coded on an ordinal scale, with values of zero, one and two representing increasing degrees of semantic generality (it is also possible to view semantic scheme one in a similar manner). For this reason, Spearman's rank order correlations were also carried out. In most cases, the relative distribution of significant and non-significant correlations between the predictor and dependent variables did not differ from those indicated by the Pearson's correlations. As the correlations were carried out to determine which variables should be entered into the regression analyses and both methods of calculation provide very similar results, Pearson's correlations are reported. In the few cases where Spearman's correlations revealed significant relations between variables that were non-significant using Pearson's correlations, additional regression analyses were carried out. All of these analyses showed that input frequency was a significant predictor of the children's verb use but semantic generality was not, thus providing further support for the current findings. 
TABLE 4. Simultaneous multivariate regression predicting age of first use of verbs in individual children's speech for all verbs present in individual mother's input samples-semantic scheme I

\begin{tabular}{|c|c|c|c|c|c|}
\hline Child & $\begin{array}{l}\text { No. of } \\
\text { verbs }\end{array}$ & Predictors & $R^{2}$ & Adj. $R^{2}$ & Final beta \\
\hline Anne & I 43 & $\begin{array}{l}\text { Input frequency } \\
\text { Semantic generality }\end{array}$ & 0.26 **** & 0.25 & $\begin{array}{l}-0.53^{* * * *} \\
0.06\end{array}$ \\
\hline Aran & 212 & $\begin{array}{l}\text { Input frequency } \\
\text { Semantic generality }\end{array}$ & $0.37^{* * * *}$ & 0.37 & $\begin{array}{c}-0.64 * * * \\
0.09\end{array}$ \\
\hline Becky & I 47 & $\begin{array}{l}\text { Input frequency } \\
\text { Semantic generality }\end{array}$ & $0.30 * * *$ & 0.29 & $\begin{array}{l}-0.57^{* * * *} \\
0.05\end{array}$ \\
\hline Dominic & $\mathrm{I}_{3} 8$ & $\begin{array}{l}\text { Input frequency } \\
\text { Semantic generality }\end{array}$ & $0.40^{* * * *}$ & 0.39 & $\begin{array}{l}-0.64^{* * * *} \\
0.02\end{array}$ \\
\hline Gail & I 83 & $\begin{array}{l}\text { Input frequency } \\
\text { Semantic generality }\end{array}$ & 0. I $8 * * *$ & 0.17 & $\begin{array}{l}-0.4 \mathrm{I} * * * \\
-0.0 \mathrm{I}\end{array}$ \\
\hline Joel & I 64 & $\begin{array}{l}\text { Input frequency } \\
\text { Semantic generality }\end{array}$ & $0.27 * * *$ & 0.26 & $\begin{array}{l}-0.53^{* * * *} \\
0.0 \mathrm{I}\end{array}$ \\
\hline $\mathrm{Liz}$ & I 46 & $\begin{array}{l}\text { Input frequency } \\
\text { Semantic generality }\end{array}$ & $0.30 * * *$ & 0.29 & $\begin{array}{l}-0.56^{* * * *} \\
0.03\end{array}$ \\
\hline Nicole & I 63 & $\begin{array}{l}\text { Input frequency } \\
\text { Semantic generality }\end{array}$ & $0.35^{* * * *}$ & 0.34 & $\begin{array}{l}-0.62 * * * \\
0.07\end{array}$ \\
\hline Ruth & I 54 & $\begin{array}{l}\text { Input frequency } \\
\text { Semantic generality }\end{array}$ & $0.37 * * *$ & 0.36 & $\begin{array}{l}-0.60 * * * \\
-0.03\end{array}$ \\
\hline
\end{tabular}

**** $p<0.001$.

related to the age of acquisition of individual verbs for all of the children, while the first measure of semantic generality was related to the age of acquisition of individual verbs for eight of the children.

Simultaneous multivariate regression analyses were then carried out to establish the relative contributions of input frequency and semantic generality to the age of acquisition of individual verbs in the children's speech. Co-linearity statistics were computed to determine whether input frequency and semantic generality were highly correlated. In all cases, the analyses suggested that co-linearity was not present in the data, indicating that it is possible to determine the relative independent contribution of each variable to the age of acquisition of individual verbs. Tables 4 and 5 show the number of verbs examined, $R^{2}$, adjusted $R^{2}$, and the final beta weight for each variable for each child. The analyses show that whilst input frequency and both measures of semantic generality correlate with the age of acquisition of individual verbs in the children's speech, once the effects of input frequency are removed, the first measure of semantic generality is not a significant predictor of the age of acquisition of verbs for any of the children. The second measure of semantic generality remains a significant predictor of the age of acquisition of particular verbs for only two of the children. Thus, although there is some limited support for the role of 
TABLE 5. Simultaneous multivariate regression predicting age of first use of verbs in individual children's speech for all verbs present in individual mother's input samples-semantic scheme 2

\begin{tabular}{|c|c|c|c|c|c|}
\hline Child & $\begin{array}{l}\text { No. of } \\
\text { verbs }\end{array}$ & Predictors & $R^{2}$ & Adj. $R^{2}$ & Final beta \\
\hline Anne & I 43 & $\begin{array}{l}\text { Input frequency } \\
\text { Semantic generality }\end{array}$ & $0.26 * * *$ & 0.25 & $\begin{array}{c}-0.53^{* * * *} \\
0.03\end{array}$ \\
\hline Aran & 212 & $\begin{array}{l}\text { Input frequency } \\
\text { Semantic generality }\end{array}$ & $0.37 * * *$ & 0.36 & $\begin{array}{l}-0.56^{* * * *} \\
-0.08\end{array}$ \\
\hline Becky & I 47 & $\begin{array}{l}\text { Input frequency } \\
\text { Semantic generality }\end{array}$ & $0.3 I^{* * * *}$ & 0.30 & $\begin{array}{l}-0.50^{* * * *} \\
-0.08\end{array}$ \\
\hline Dominic & I 38 & $\begin{array}{l}\text { Input frequency } \\
\text { Semantic generality }\end{array}$ & $0.44^{* * * *}$ & 0.43 & $\begin{array}{l}-0.5 \mathrm{I}^{* * *} \\
-0.23^{* *}\end{array}$ \\
\hline Gail & I 83 & $\begin{array}{l}\text { Input frequency } \\
\text { Semantic generality }\end{array}$ & O. I $9^{* * *}$ & O.I 8 & $\begin{array}{l}-0.36^{* * * *} \\
-0.1 \mathrm{I}\end{array}$ \\
\hline Joel & I 64 & $\begin{array}{l}\text { Input frequency } \\
\text { Semantic generality }\end{array}$ & $0.28 * * *$ & 0.27 & $\begin{array}{l}-0.47^{* * * *} \\
-0.09\end{array}$ \\
\hline $\mathrm{Liz}$ & I 46 & $\begin{array}{l}\text { Input frequency } \\
\text { Semantic generality }\end{array}$ & $0.30 * * *$ & 0.29 & $\begin{array}{l}-0.48^{* * * *} \\
-0.1 \mathrm{I}\end{array}$ \\
\hline Nicole & 163 & $\begin{array}{l}\text { Input frequency } \\
\text { Semantic generality }\end{array}$ & 0.36 **** & 0.35 & $\begin{array}{l}-0.5 \mathrm{I} * * * \\
-0.12\end{array}$ \\
\hline Ruth & I 54 & $\begin{array}{l}\text { Input frequency } \\
\text { Semantic generality }\end{array}$ & $0.44 * * *$ & 0.44 & $\begin{array}{l}-0.42 * * * \\
-0.33 * * *\end{array}$ \\
\hline
\end{tabular}

** $p<0.01 ; * * * * 00.001$.

semantic generality in acquisition, where it is possible to tease apart the relative contributions of input frequency and semantic generality, the semantic status of individual verbs is not a significant predictor of early verb acquisition. $^{4}$

The role of semantically general verbs in the acquisition of specific syntactic structures. Zero-order correlations were calculated to establish whether input frequency and semantic generality were related to the age of acquisition of individual verbs in the VO, SVO and intransitive constructions in the children's speech over the whole year (see Table 6). Simultaneous multivariate regression analyses were then carried out to establish the relative contributions of input frequency and semantic generality to the age of acquisition of individual verbs in specific constructions in the children's

[4] It is possible that these analyses are unduly influenced by those verbs that were not acquired by the children during the study and were assigned an age of acquisition of seven days after the end of the study. The analyses were therefore repeated on only the verbs acquired by individual children. The results were very similar to those reported; although input frequency was a significant predictor of age of acquisition for all the children, the first measure of semantic generality was not a significant predictor of age of acquisition for any of the children, and the second measure of semantic generality was a significant predictor of age of acquisition for only two of the children. 
TABLE 6. Correlations between age of first use, input frequency, and two measures of semantic generality for verbs in the VO, SVO and intransitive constructions produced by individual children

\begin{tabular}{|c|c|c|c|c|c|}
\hline \multirow[b]{2}{*}{ Child } & \multicolumn{3}{|c|}{ Age of first use and: } & \multicolumn{2}{|c|}{ Input frequency and: } \\
\hline & $\begin{array}{c}\text { Input } \\
\text { frequency }\end{array}$ & $\begin{array}{l}\text { Semantic } \\
\text { scheme I }\end{array}$ & $\begin{array}{l}\text { Semantic } \\
\text { scheme } 2\end{array}$ & $\begin{array}{l}\text { Semantic } \\
\text { scheme I }\end{array}$ & $\begin{array}{l}\text { Semantic } \\
\text { scheme } 2\end{array}$ \\
\hline \multicolumn{6}{|l|}{ VO } \\
\hline Anne & $-0.33^{* *}$ & -0.12 & -0.14 & $0.44^{* * * *}$ & $0.55^{* * * *}$ \\
\hline Aran & $-0.34^{* *}$ & -0.16 & $-0.28 *$ & $0.46^{* * * *}$ & $0.55^{* * *}$ \\
\hline Becky & $-0.30^{*}$ & -0.16 & -0.20 & $0.5 \mathrm{I} * * *$ & 0.56 **** \\
\hline Dominic & $-0.53 * * *$ & -0.25 & $-0.2 \mathrm{I}$ & $0.48 * * *$ & $0.52^{* * * *}$ \\
\hline Gail & $-0.32^{* *}$ & -0.13 & $-0.26^{*}$ & $0.52^{* * * *}$ & $0.64 * * *$ \\
\hline Joel & $-0.47^{* * * *}$ & -0.15 & -0.22 & $0.32^{* * * *}$ & $0.52^{* * * *}$ \\
\hline $\mathrm{Liz}$ & $-0.43^{* *}$ & -0.24 & $-0.40^{* *}$ & $0.50 * *$ & $0.67 * * *$ \\
\hline Nicole & $-0.39 * * *$ & -0.23 & $-0.39 * * *$ & $0.46 * * *$ & $0.53 * * *$ \\
\hline Ruth & $-0.4 I^{* *}$ & -0.19 & $-0.49^{* * * *}$ & $0.49 * * *$ & $0.60 * * *$ \\
\hline \multicolumn{6}{|l|}{ SVO } \\
\hline Anne & $-0.4 \mathrm{I}^{* *}$ & -0.17 & -0.26 & $0.47 * * *$ & $0.63 * * *$ \\
\hline Aran & $-0.55 * * *$ & $-0.26^{*}$ & $-0.40^{* *}$ & $0.47^{* * * *}$ & 0.57 **** \\
\hline Becky & $-0.37^{* *}$ & -0.25 & $-0.5 \mathrm{I} * * *$ & $0.47 * * *$ & $0.56^{* * * *}$ \\
\hline Dominic & $-0.6 \mathrm{I} * * *$ & $-0.36^{*}$ & $-0.33^{* *}$ & $0.55^{* * * *}$ & $0.63 * * *$ \\
\hline Gail & $-0.38 * *$ & -0.19 & $-0.35^{* *}$ & $0.54^{* * * *}$ & $0.7 I^{* * * *}$ \\
\hline Joel & $-0.4 \mathrm{I} * * *$ & -0.23 & $-0.30 *$ & $0.32^{* *}$ & $0.54 * * *$ \\
\hline $\mathrm{Liz}$ & $-0.56 * * *$ & $-0.36^{*}$ & $-0.55^{* * * *}$ & $0.50 * * *$ & $0.72 * * *$ \\
\hline Nicole & $-0.53 * * *$ & $-0.36 * *$ & $-0.49 * *$ & $0.45 * * *$ & $0.55 * * *$ \\
\hline Ruth & $-0.40^{* * *}$ & $-0.32^{*}$ & $-0.59 * * *$ & $0.47 * * *$ & $0.62 * * *$ \\
\hline \multicolumn{6}{|l|}{ Intransitive } \\
\hline Anne & $-0.4 \mathrm{I}^{* *}$ & -0.17 & -0.09 & $0.37 * * *$ & $0.30 * *$ \\
\hline Aran & $-0.44^{* *}$ & $-0.2 \mathrm{I}$ & $-0.28^{*}$ & $0.49^{* * * *}$ & $0.40 * * *$ \\
\hline Becky & $-0.3^{* * *}$ & -0.23 & -0.25 & $0.53 * * *$ & 0.46 **** \\
\hline Dominic & $-0.44^{* *}$ & -0.32 & $-0.3 I$ & 0.19 & 0.19 \\
\hline Gail & $-0.50^{* * * *}$ & -0.22 & $-0.3^{6 * *}$ & $0.47^{* * * *}$ & $0.44^{* * * *}$ \\
\hline Joel & $-0.34^{*}$ & -0.17 & $-0.29^{*}$ & $0.49 * * *$ & $0.42 * * *$ \\
\hline $\mathrm{Liz}$ & $-0.56^{* * * *}$ & -0.27 & $-0.45^{* *}$ & $0.56 * * *$ & $0.48 * * *$ \\
\hline Nicole & $-0.46 * * *$ & $-0.28 *$ & $-0.38^{* *}$ & $0.43^{* * * *}$ & $0.4 I^{* * * *}$ \\
\hline Ruth & $-0.69 * * *$ & $-0.44^{* *}$ & $-0.34^{*}$ & $0.27 * * *$ & $0.43^{* * * *}$ \\
\hline
\end{tabular}

* $p<0.05 ; * * p<0.01 ; * * * p<0.001$.

speech. Tables 7 and 8 show the number of verbs examined, $R^{2}$, adjusted $R^{2}$, and the final beta weight for each variable for each child for each syntactic construction. The analyses show that once the effects of input frequency are removed, the first measure of semantic generality is not a significant predictor of the age of acquisition of verbs for any of the children in the $\mathrm{VO}, \mathrm{SVO}$ or intransitive constructions. The second measure of semantic generality remains a significant predictor of the age of acquisition of verbs in the $\mathrm{VO}$ construction for two children, in the SVO construction 
for three children, and in the intransitive construction for none of the children. These findings show that the semantic status of individual verbs is not a significant predictor of the age of acquisition of individual verbs in the VO, SVO and intransitive constructions over and above the effects of input frequency.

\section{Syntactic diversity in the input, semantic generality and syntactic diversity} in the children's speech

The hypothesis that semantic generality influences the syntactic diversity of use of individual verbs in the children's Stage I speech was then examined. Table 9 shows the mean number of verb frames produced per verb in the children's Stage I data and in the mothers' data. First, the number of different verb frames produced with general and more specific verbs in the children's speech was compared once the effects of the frequency of individual verbs in the children's speech had been partialled out. ANCOVAs revealed that for each measure of semantic generality, for seven of the children there were no significant differences in the number of different verb frames produced with semantically general and more specific verbs (Scheme I $\operatorname{Liz} F(\mathrm{I}, 44)=9.77, p<0.0$ I, Nicole $F(\mathrm{I}, 88)=$ I $7.07, p<0.0$ I; non-significant $F$ values range between $0.0 \mathrm{I}$ and 2.57. Scheme 2 Joel $F(2,59)=5.44, p<0.01$, Nicole $F(2,87)=4.8 \mathrm{I}, p<0.05 ;$ non-significant $F$ values range between 0.08 and $2 \cdot 04)$.

Given that there were no consistent differences between semantically general and more specific verbs with respect to the number of different verb frames in which they appeared in the children's speech, the input was examined to establish whether factors in the input might influence the children's verb use. Zero-order correlations were calculated to establish whether there was a relation between syntactic diversity in the input, semantic generality, and syntactic diversity in the children's speech. Simultaneous multivariate regression analyses were then carried out to determine the extent to which syntactic diversity in the input and semantic generality predict syntactic diversity with individual verbs in the children's speech for those children where either measure correlated significantly with syntactic diversity in their speech. Because the frequency of use of individual verbs in the children's speech might also be expected to influence the number of frames in which individual verbs appeared in the children's speech, verb frequency in the children's speech was also entered into the regression model. As the frequency distribution of verbs in the children's speech was skewed, log transformations were applied to the frequency data. Tables io and I I show the $R^{2}$, adjusted $R^{2}$, and the final beta weight for each variable for the relevant children.

The analyses show that for semantic categorization scheme $\mathrm{I}$, for five children verb frequency in their speech is the only predictor of syntactic 
TABLE 7. Simultaneous multivariate regression predicting age of first use of verbs in the VO, SVO and intransitive constructions in individual children's speech-semantic scheme I

\begin{tabular}{|c|c|c|c|c|c|}
\hline Child & $\begin{array}{l}\text { No. of } \\
\text { verbs }\end{array}$ & Predictors & $R^{2}$ & Adj. $R^{2}$ & Final beta \\
\hline \multicolumn{6}{|l|}{ VO } \\
\hline Anne & 67 & $\begin{array}{l}\text { Input frequency } \\
\text { Semantic generality }\end{array}$ & O. I I* & 0.08 & $\begin{array}{l}-0.33^{*} \\
-0.00\end{array}$ \\
\hline Aran & 69 & $\begin{array}{l}\text { Input frequency } \\
\text { Semantic generality }\end{array}$ & $0.12 *$ & 0.09 & $\begin{array}{l}-0.33^{*} \\
-0.03\end{array}$ \\
\hline Becky & 65 & $\begin{array}{l}\text { Input frequency } \\
\text { Semantic generality }\end{array}$ & $0.09^{*}$ & 0.06 & $\begin{array}{l}-0.29^{*} \\
-0.03\end{array}$ \\
\hline Dominic & 45 & $\begin{array}{l}\text { Input frequency } \\
\text { Semantic generality }\end{array}$ & $0.29 * * *$ & 0.25 & $\begin{array}{c}-0.56^{* * * *} \\
0.06\end{array}$ \\
\hline Gail & 82 & $\begin{array}{l}\text { Input frequency } \\
\text { Semantic generality }\end{array}$ & $0.10 *$ & 0.08 & $\begin{array}{c}-0.33^{* *} \\
0.02\end{array}$ \\
\hline Joel & 70 & $\begin{array}{l}\text { Input frequency } \\
\text { Semantic generality }\end{array}$ & $0.22 * * *$ & 0.20 & $\begin{array}{l}-0.47^{* * * *} \\
-0.0 \mathrm{I}\end{array}$ \\
\hline $\mathrm{Liz}$ & 45 & $\begin{array}{l}\text { Input frequency } \\
\text { Semantic generality }\end{array}$ & $0.18^{*}$ & 0.14 & $\begin{array}{l}-0.40^{*} \\
-0.04\end{array}$ \\
\hline Nicole & 65 & $\begin{array}{l}\text { Input frequency } \\
\text { Semantic generality }\end{array}$ & $0.16 * *$ & $0 \cdot 13$ & $\begin{array}{l}-0.36^{* *} \\
-0.06\end{array}$ \\
\hline Ruth & 43 & $\begin{array}{l}\text { Input frequency } \\
\text { Semantic generality }\end{array}$ & $0 \cdot 16^{*}$ & 0.12 & $\begin{array}{l}-0.40^{*} \\
-0.02\end{array}$ \\
\hline \multicolumn{6}{|l|}{ SVO } \\
\hline Anne & $5^{I}$ & $\begin{array}{l}\text { Input frequency } \\
\text { Semantic generality }\end{array}$ & $0.17^{*}$ & 0.13 & $\begin{array}{l}-0.40^{* *} \\
-0.02\end{array}$ \\
\hline Aran & 79 & $\begin{array}{l}\text { Input frequency } \\
\text { Semantic generality }\end{array}$ & $0.3 I^{* * * *}$ & 0.29 & $\begin{array}{l}-0.53^{* * * *} \\
-0.05\end{array}$ \\
\hline Becky & 56 & $\begin{array}{l}\text { Input frequency } \\
\text { Semantic generality }\end{array}$ & $0 \cdot 14^{*}$ & O. I I & $\begin{array}{l}-0.32^{*} \\
-0.1 \mathrm{I}\end{array}$ \\
\hline Dominic & 47 & $\begin{array}{l}\text { Input frequency } \\
\text { Semantic generality }\end{array}$ & $0.37^{* * * *}$ & 0.34 & $\begin{array}{l}-0.59^{* * * *} \\
-0.04\end{array}$ \\
\hline Gail & $5^{8}$ & $\begin{array}{l}\text { Input frequency } \\
\text { Semantic generality }\end{array}$ & $0.14^{*}$ & O. I I & $\begin{array}{l}-0.37^{*} \\
-0.01\end{array}$ \\
\hline Joel & 64 & $\begin{array}{l}\text { Input frequency } \\
\text { Semantic generality }\end{array}$ & o. I $8 * *$ & $0 \cdot 16$ & $\begin{array}{l}-0.38 * * \\
-0.12\end{array}$ \\
\hline $\mathrm{Liz}$ & 46 & $\begin{array}{l}\text { Input frequency } \\
\text { Semantic generality }\end{array}$ & $0.32^{* * * *}$ & 0.28 & $\begin{array}{l}-0.50^{* * *} \\
-0.1 \mathrm{I}\end{array}$ \\
\hline Nicole & 55 & $\begin{array}{l}\text { Input frequency } \\
\text { Semantic generality }\end{array}$ & $0.30 * * *$ & 0.27 & $\begin{array}{l}-0.47^{* *} \\
-0.14\end{array}$ \\
\hline Ruth & 42 & $\begin{array}{l}\text { Input frequency } \\
\text { Semantic generality }\end{array}$ & $0.19^{*}$ & 0.15 & $\begin{array}{l}-0.32^{*} \\
-0.20\end{array}$ \\
\hline \multicolumn{6}{|l|}{ Intransitive } \\
\hline Anne & 54 & $\begin{array}{l}\text { Input frequency } \\
\text { Semantic generality }\end{array}$ & $0.17^{* * *}$ & 0.14 & $\begin{array}{c}-0.43^{* *} \\
0.04\end{array}$ \\
\hline Aran & $5^{8}$ & $\begin{array}{l}\text { Input frequency } \\
\text { Semantic generality }\end{array}$ & O. I $9^{* *}$ & $0 \cdot 16$ & $\begin{array}{l}-0.47^{* *} \\
0.06\end{array}$ \\
\hline Becky & 55 & $\begin{array}{l}\text { Input frequency } \\
\text { Semantic generality }\end{array}$ & O. I $5^{*}$ & O. I I & $\begin{array}{l}-0.38^{*} \\
-0.0 \mathrm{I}\end{array}$ \\
\hline Dominic & 33 & $\begin{array}{l}\text { Input frequency } \\
\text { Semantic generality }\end{array}$ & $0.2 I^{*}$ & 0.16 & $\begin{array}{l}-0.38^{*} \\
-0.14\end{array}$ \\
\hline
\end{tabular}


TABLE 7. (Cont.)

\begin{tabular}{|c|c|c|c|c|c|}
\hline Child & $\begin{array}{l}\text { No. of } \\
\text { verbs }\end{array}$ & Predictors & $R^{2}$ & Adj. $R^{2}$ & Final beta \\
\hline Gail & 60 & $\begin{array}{l}\text { Input frequency } \\
\text { Semantic generality }\end{array}$ & $0.26 * * *$ & 0.23 & $\begin{array}{l}-0.52^{* * * *} \\
0.04\end{array}$ \\
\hline Joel & 54 & $\begin{array}{l}\text { Input frequency } \\
\text { Semantic generality }\end{array}$ & O.II* & 0.08 & $\begin{array}{c}-0.34^{*} \\
0.01\end{array}$ \\
\hline $\mathrm{Liz}$ & 46 & $\begin{array}{l}\text { Input frequency } \\
\text { Semantic generality }\end{array}$ & $0.32 * * *$ & 0.29 & $\begin{array}{l}-0.6 \mathrm{I} * * * \\
0.09\end{array}$ \\
\hline Nicole & 50 & $\begin{array}{l}\text { Input frequency } \\
\text { Semantic generality }\end{array}$ & $0.2 \mathrm{I} * *$ & $0 \cdot 18$ & $\begin{array}{l}-0.47^{* * *} \\
0.01\end{array}$ \\
\hline Ruth & 34 & $\begin{array}{l}\text { Input frequency } \\
\text { Semantic generality }\end{array}$ & $0.48 * * *$ & 0.45 & $\begin{array}{l}-0.63 * * * \\
-0.1 \mathrm{I}\end{array}$ \\
\hline
\end{tabular}

* $p<0.05 ; * * 0<0.01 ; * * * p<0.001$.

diversity. For one child syntactic diversity in the input remains a significant predictor of syntactic diversity in her speech, and for two children, semantic generality remains a significant predictor of syntactic diversity in their speech. For semantic categorization scheme 2, for four children, verb frequency in their speech is the only significant predictor of syntactic diversity. For three children syntactic diversity in the input remains a significant predictor of syntactic diversity in their speech, and for one child semantic generality remains a significant predictor of syntactic diversity in his speech. Thus, whilst both semantic generality and syntactic diversity in the input may play a limited role in determining the syntactic diversity of individual verbs for some children, neither factor consistently determines syntactic diversity in the children's speech once we have controlled for sample size (frequency of verb use) in the children's speech.

\section{Preferential use of semantically general verbs in children's speech}

The hypothesis that children might rely more heavily on semantically general verbs at Stage I than adults because children use general verbs in place of more specific verb forms they have not yet acquired was tested for both groups of semantically general verbs. The proportional use of semantically general verbs as a function of total verb tokens was calculated for the children and the mothers and the two groups compared. $T$-tests revealed that for the first semantic classification scheme, the mothers used a significantly higher proportion of semantically general verbs in their speech than the children (Group I, children $M=30 \cdot 7$, S.D. $=8 \cdot 8$, mothers $M=38 \cdot 5$, S.D. $=4 \cdot \mathrm{I}, t(\mathrm{I} 6)=-2 \cdot 4 \mathrm{I}, p<0.05)$, while for the second scheme there was no difference between the mothers and children in their proportional use of semantically general verbs (Group 2, children $M=50 \cdot 2, S . D .=8 \cdot 2$, mothers $M=55 \cdot 2, S . D .=4 \cdot 3, t(\mathrm{I} 6)=-\mathrm{I} \cdot 62, p>0 \cdot 05)$. 
TABLE 8. Simultaneous multivariate regression predicting age of first use of verbs in the VO, SVO and intransitive constructions in individual children's speech-semantic scheme 2

\begin{tabular}{|c|c|c|c|c|c|}
\hline Child & $\begin{array}{l}\text { No. of } \\
\text { verbs }\end{array}$ & Predictors & $R^{2}$ & Adj. $R^{2}$ & Final beta \\
\hline \multicolumn{6}{|l|}{$\mathrm{VO}$} \\
\hline \multirow[t]{2}{*}{ Anne } & \multirow[t]{2}{*}{67} & Input frequency & \multirow[t]{2}{*}{ O. I I* } & \multirow[t]{2}{*}{0.08} & $-0.35^{*}$ \\
\hline & & Semantic generality & & & 0.34 \\
\hline \multirow[t]{2}{*}{ Aran } & \multirow[t]{2}{*}{69} & Input frequency & \multirow[t]{2}{*}{ O. I $3 * *$} & \multirow[t]{2}{*}{ O. I I } & $-0.26^{*}$ \\
\hline & & Semantic generality & & & -0.15 \\
\hline \multirow[t]{2}{*}{ Becky } & \multirow[t]{2}{*}{65} & Input frequency & \multirow[t]{2}{*}{$0 \cdot 10^{*}$} & \multirow[t]{2}{*}{0.07} & -0.27 \\
\hline & & Semantic generality & & & -0.06 \\
\hline \multirow[t]{2}{*}{ Dominic } & \multirow[t]{2}{*}{45} & Input frequency & \multirow[t]{2}{*}{$0.29 * * *$} & \multirow[t]{2}{*}{0.25} & $-0.57 * * *$ \\
\hline & & Semantic generality & & & 0.07 \\
\hline \multirow[t]{2}{*}{ Gail } & \multirow[t]{2}{*}{82} & Input frequency & \multirow[t]{2}{*}{ O. I I ** } & \multirow[t]{2}{*}{0.09} & $-0.26 *$ \\
\hline & & Semantic generality & & & -0.10 \\
\hline \multirow{2}{*}{ Joel } & 70 & Input frequency & $0.22 * * *$ & 0.20 & $-0.47 * * *$ \\
\hline & & Semantic generality & & & -0.01 \\
\hline $\mathrm{Liz}$ & 45 & Input frequency & $0.20 * *$ & $0 \cdot 16$ & -0.29 \\
\hline & & Semantic generality & & & -0.20 \\
\hline Nicole & 65 & Input frequency & $0.20 * * *$ & 0.18 & $-0.26^{*}$ \\
\hline & & Semantic generality & & & $-0.26^{*}$ \\
\hline Ruth & 43 & Input frequency & $0.27^{* *}$ & 0.24 & $-0.2 \mathrm{I}$ \\
\hline & & Semantic generality & & & $-0.38^{*}$ \\
\hline SVO & & & & & \\
\hline Anne & $5 \mathrm{I}$ & Input frequency & $0 \cdot 17^{*}$ & $0 \cdot 13$ & $-0 \cdot 39^{*}$ \\
\hline & & Semantic generality & & & -0.02 \\
\hline Aran & 79 & Input frequency & $0.32 * * *$ & 0.30 & $-0.47 * * *$ \\
\hline & & Semantic generality & & & -0.16 \\
\hline Becky & 56 & Input frequency & $0.28 * * *$ & 0.25 & $-0 . I_{5}$ \\
\hline & & Semantic generality & & & $-0.44^{* *}$ \\
\hline Dominic & 47 & Input frequency & $0.37^{* * * *}$ & 0.34 & $-0.64^{* * *}$ \\
\hline & & Semantic generality & & & -0.04 \\
\hline Gail & 58 & Input frequency & $0 \cdot 16 * *$ & O.I 3 & -0.26 \\
\hline & & Semantic generality & & & -0.17 \\
\hline Joel & 64 & Input frequency & O. I $9^{* *}$ & $0 \cdot 16$ & $-0.35^{* *}$ \\
\hline & & Semantic generality & & & $-0 \cdot 14$ \\
\hline $\mathrm{Liz}$ & 46 & Input frequency & $0.36 * * *$ & 0.33 & $-0.34^{*}$ \\
\hline & & Semantic generality & & & $-0.3 I$ \\
\hline Nicole & 55 & Input frequency & $0.35^{* * * *}$ & 0.32 & $-0 \cdot 39^{* *}$ \\
\hline & & Semantic generality & & & $-0.30 *$ \\
\hline Ruth & 42 & Input frequency & $0.37^{* * * *}$ & 0.34 & $-0 \cdot 16$ \\
\hline & & Semantic generality & & & $-0.52^{* * *}$ \\
\hline Intransitive & & & & & \\
\hline Anne & 54 & Input frequency & $\mathrm{O} . \mathrm{I} 8 * *$ & 0.15 & $-0.46^{* *}$ \\
\hline & & Semantic generality & & & O. I I \\
\hline Aran & 58 & Input frequency & $0.20 * *$ & 0.17 & $-0.39^{* *}$ \\
\hline & & Semantic generality & & & $-0 \cdot I_{1}$ \\
\hline Becky & 55 & Input frequency & $0.15^{*}$ & O. I I & $-0.35^{*}$ \\
\hline & & Semantic generality & & & -0.06 \\
\hline Dominic & 33 & Input frequency & $0.23^{*}$ & $0 \cdot 18$ & $-0.38 *$ \\
\hline & & Semantic generality & & & -0.18 \\
\hline
\end{tabular}


TABLE 8. (Cont.)

\begin{tabular}{|c|c|c|c|c|c|}
\hline Child & $\begin{array}{l}\text { No. of } \\
\text { verbs }\end{array}$ & Predictors & $R^{2}$ & Adj. $R^{2}$ & Final beta \\
\hline Gail & 60 & $\begin{array}{l}\text { Input frequency } \\
\text { Semantic generality }\end{array}$ & $0.27 * * *$ & 0.25 & $\begin{array}{l}-0.42^{* * *} \\
-0.16\end{array}$ \\
\hline Joel & 54 & $\begin{array}{l}\text { Input frequency } \\
\text { Semantic generality }\end{array}$ & $0.14 *$ & O.I I & $\begin{array}{l}-0.26 \\
-0.18\end{array}$ \\
\hline $\mathrm{Liz}$ & 46 & $\begin{array}{l}\text { Input frequency } \\
\text { Semantic generality }\end{array}$ & $0.34^{* * * *}$ & 0.30 & $\begin{array}{l}-0.45^{* * *} \\
-0.18\end{array}$ \\
\hline Nicole & 50 & $\begin{array}{l}\text { Input frequency } \\
\text { Semantic generality }\end{array}$ & $0 \cdot 24^{* *}$ & 0.21 & $\begin{array}{l}-0.36^{*} \\
-0.19\end{array}$ \\
\hline Ruth & 34 & $\begin{array}{l}\text { Input frequency } \\
\text { Semantic generality }\end{array}$ & $0.47 * * *$ & 0.44 & $\begin{array}{l}-0.7 \mathrm{I} * * * * \\
0.04\end{array}$ \\
\hline
\end{tabular}

* $p<0.05 ; * * 1<0.01 ; * * * p<0.001$.

TABLE 9. Mean number of frames per verb in the children's Stage I data and in the mothers' speech

\begin{tabular}{lcccc}
\hline & $\begin{array}{c}\text { Mean no. } \\
\text { frames/verb } \\
\text { in children's } \\
\text { Stage I data }\end{array}$ & S.D. & $\begin{array}{c}\text { Mean no. } \\
\text { frames/verb in } \\
\text { input sample } \\
\text { (for verbs acquired } \\
\text { by children at Stage I) }\end{array}$ & S.D. \\
\hline Anne & $2 \cdot 42$ & $2 \cdot 00$ & $3 \cdot 7 \mathrm{I}$ & $3 \cdot 75$ \\
Aran & $2 \cdot 22$ & $\mathrm{I} \cdot 73$ & $4 \cdot 52$ & $4 \cdot \mathrm{I} 6$ \\
Becky & $2 \cdot 30$ & $\mathrm{I} \cdot 72$ & $3 \cdot 03$ & $3 \cdot 63$ \\
Dominic & $2 \cdot 6 \mathrm{I}$ & $\mathrm{I} \cdot 78$ & $3 \cdot 50$ & $3 \cdot 85$ \\
Gail & $\mathrm{I} \cdot 83$ & $\mathrm{I} \cdot 46$ & $3 \cdot 79$ & $4 \cdot \mathrm{I} 6$ \\
Joel & $\mathrm{I} \cdot 92$ & $\mathrm{I} \cdot 36$ & $3 \cdot 40$ & $3 \cdot 63$ \\
Liz & $2 \cdot 2 \mathrm{I}$ & $\mathrm{I} \cdot 90$ & $3 \cdot 86$ & $4 \cdot 29$ \\
Nicole & $2 \cdot 93$ & $2 \cdot 64$ & $3 \cdot 16$ & $4 \cdot 08$ \\
Ruth & $3 \cdot 72$ & $2 \cdot 78$ & $6 \cdot 86$ & $5 \cdot 24$ \\
\hline
\end{tabular}

From these results, it is unclear whether the high proportional use of semantically general verbs in the mothers' speech might reflect a tendency to use these verbs in place of more specific verbs. If this was the case, the similarly high proportional use of semantically general verbs in the children's speech could reflect their use of semantically general verbs in place of more specific verbs. The children's and mothers' data were therefore compared with the proportional use of semantically general verbs in a sample of adult conversation (Lancaster/IBM corpus of spoken English). ${ }^{5}$ In this

[5] The Lancaster/IBM corpus of spoken English (generated by the Department of Linguistics and Modern English Language, University of Lancaster and IBM UK Scientific Centre, Winchester; supplied by International Computer Archive of Modern English (ICAME)) is a corpus of spoken British-English tagged for grammatical 
TABLE Iо. Simultaneous multivariate regression predicting the syntactic diversity of individual verbs in the children's stage I speech-semantic categorization scheme I

\begin{tabular}{|c|c|c|c|c|}
\hline Child & Predictors & $R^{2}$ & Adj. $R^{2}$ & Final beta \\
\hline \multirow[t]{3}{*}{ Anne } & Frequency in child's speech & $0.65^{* * *}$ & 0.64 & $0.80 * * *$ \\
\hline & Syntactic diversity in the input & & & 0.00 \\
\hline & Semantic generality & & & 0.03 \\
\hline \multirow[t]{3}{*}{ Aran } & Frequency in child's speech & $0.76^{* * * *}$ & 0.74 & $0.8 \mathrm{I} * * *$ \\
\hline & Syntactic diversity in the input & & & O.II \\
\hline & Semantic generality & & & -0.02 \\
\hline \multirow{3}{*}{ Becky } & Frequency in child's speech & $0.68 * * * *$ & 0.67 & $0.57 * * *$ \\
\hline & Syntactic diversity in the input & & & $0.37 * * *$ \\
\hline & Semantic generality & & & -0.05 \\
\hline \multirow[t]{3}{*}{ Dominic } & Frequency in child's speech & $0.67 * * *$ & 0.65 & $0.84 * * *$ \\
\hline & Syntactic diversity in the input & & & -0.04 \\
\hline & Semantic generality & & & -0.02 \\
\hline \multirow[t]{3}{*}{ Gail } & Frequency in child's speech & $0.62 * * *$ & 0.60 & $0.72^{* * * *}$ \\
\hline & Syntactic diversity in the input & & & 0.06 \\
\hline & Semantic generality & & & 0.05 \\
\hline \multirow[t]{3}{*}{ Joel } & Frequency in child's speech & $0.60 * * *$ & 0.58 & $0.73^{* * *}$ \\
\hline & Syntactic diversity in the input & & & 0.09 \\
\hline & Semantic generality & & & -0.03 \\
\hline \multirow[t]{3}{*}{$\mathrm{Liz}$} & Frequency in child's speech & $0.70 * * *$ & 0.68 & $0.54^{* * * *}$ \\
\hline & Syntactic diversity in the input & & & 0.18 \\
\hline & Semantic generality & & & $0.23^{*}$ \\
\hline \multirow[t]{3}{*}{ Nicole } & Frequency in child's speech & $0.82 * * *$ & $0.8 \mathrm{I}$ & $0.72^{* * * *}$ \\
\hline & Syntactic diversity in the input & & & 0.12 \\
\hline & Semantic generality & & & $0 \cdot 16^{*}$ \\
\hline
\end{tabular}

* $p<0.05$; *** $p<0.001$.

sample, 28.7 and $50 \cdot 0 \%$ of verb tokens consisted of semantically general verbs for semantic schemes I and 2 respectively, compared with the slightly higher proportional use of these verbs in the mothers' speech. This suggests that the mothers may use semantically general verbs in place of more specific verbs to a limited extent, making it difficult to determine whether semantic generality or input frequency determines the children's verb use. ${ }^{6}$ However, the close similarity in the proportional use of semantically general

category. Included in the corpus are 6 corpora of adult-adult dialogue. These corpora, containing 6826 words and just over 500 verb uses excluding the copula, were coded and the proportional use of semantically general verbs as a function of total verb use calculated for each semantic categorization scheme.

[6] In fact, the high proportional use of semantically general verbs in the mothers' speech seems to reflect a disproportionately frequent use of the phrases 'Are you going to V?' and 'What/Where're you going to V?' compared to adult-adult speech and the children's speech. This suggests that the mothers are not adapting their speech to use semantically general verbs in place of more specific verbs, but rather that they are asking a lot of questions specific to the pragmatics of interacting with children that include the semantically general verb ' $\mathrm{go}$ '. 
TABLE I I. Simultaneous multivariate regression predicting the syntactic diversity of individual verbs in the children's stage I speech-semantic categorization scheme 2

\begin{tabular}{|c|c|c|c|c|}
\hline Child & Predictors & $R^{2}$ & Adj. $R^{2}$ & Final beta \\
\hline Anne & $\begin{array}{l}\text { Frequency in child's speech } \\
\text { Syntactic diversity in the input } \\
\text { Semantic generality }\end{array}$ & $0.66 * * *$ & 0.64 & $\begin{array}{l}0.79^{* * * *} \\
0.08 \\
-0.09\end{array}$ \\
\hline Aran & $\begin{array}{l}\text { Frequency in child's speech } \\
\text { Syntactic diversity in the input } \\
\text { Semantic generality }\end{array}$ & $0.76 * * *$ & 0.75 & $\begin{array}{l}0.83^{* * * *} \\
0.03 \\
0.10\end{array}$ \\
\hline Becky & $\begin{array}{l}\text { Frequency in child's speech } \\
\text { Syntactic diversity in the input } \\
\text { Semantic generality }\end{array}$ & $0.69^{* * * *}$ & 0.68 & $\begin{array}{l}0.60 * * * \\
0.40 * * * \\
-0.12\end{array}$ \\
\hline Dominic & $\begin{array}{l}\text { Frequency in child's speech } \\
\text { Syntactic diversity in the input } \\
\text { Semantic generality }\end{array}$ & $0.68 * * *$ & 0.65 & $\begin{array}{l}-0.12 \\
0.84^{* * * *} \\
-0.00 \\
-0.08\end{array}$ \\
\hline Gail & $\begin{array}{l}\text { Frequency in child's speech } \\
\text { Syntactic diversity in the input } \\
\text { Semantic generality }\end{array}$ & $0.62 * * *$ & $0.6 \mathrm{I}$ & $\begin{array}{l}0.74^{* * * *} \\
0.17 \\
-0.14\end{array}$ \\
\hline Joel & $\begin{array}{l}\text { Frequency in child's speech } \\
\text { Syntactic diversity in the input } \\
\text { Semantic generality }\end{array}$ & $0.66^{* * * *}$ & 0.64 & $\begin{array}{l}0.62 * * * \\
-0.54 \\
0.31 * * *\end{array}$ \\
\hline $\mathrm{Liz}$ & $\begin{array}{l}\text { Frequency in child's speech } \\
\text { Syntactic diversity in the input } \\
\text { Semantic generality }\end{array}$ & $0.67 * * *$ & 0.64 & $\begin{array}{l}0.55^{* * *} \\
0.36^{*} \\
-0.05\end{array}$ \\
\hline Nicole & $\begin{array}{l}\text { Frequency in child's speech } \\
\text { Syntactic diversity in the input } \\
\text { Semantic generality }\end{array}$ & $0.82 * * * *$ & $0.8 \mathrm{I}$ & $\begin{array}{l}0.67 * * * \\
0.19 * * \\
0.12\end{array}$ \\
\hline
\end{tabular}

* $p<0.05$; ** $p<0.01$; **** $p<0.001$.

verbs in the children's speech and in adult conversation suggests that these verbs are not playing a special role in children's early language due to their semantic generality.

\section{Syntactic accuracy as a function of semantic generality}

The final hypothesis was that if semantically general verbs are privileged in a way that aids the acquisition of syntax, children should make fewer grammatical errors with these verbs than with other semantically more specific verbs with respect to their provision of obligatory subject and direct object arguments at Stage I. As the data were not normally distributed, non-parametric tests were used. To examine whether the children were less likely to make grammatical errors with regard to subject omission with semantically general verbs than with more specific verbs, the proportional subject provision with individual verbs in each child's speech was compared across semantic groups. 
For the first measure of semantic generality, Mann-Whitney tests for two independent samples revealed that there were no differences in the level of subject provision between the semantically general ( $M$ values ranged from $29 \cdot 6$ to $65 \cdot 8 \%$ ) and more specific verbs ( $M$ values ranged from i 9.9 to $62 \cdot 4 \%$ ) for all but one of the children (Lucy $z=-2 \cdot \mathrm{I}$ I,$p<0.05$; nonsignificant $z$ values ranged between $0 \cdot 19$ and $I \cdot 84$ ). For the second measure of semantic generality, Kruskal-Wallis tests for multiple independent samples revealed that there were no differences between light ( $M$ values ranged from 28.3 to $54.8 \%$ ), part-light ( $M$ values ranged from 17.5 to $50 \cdot 0 \%$ ), and non-light verbs ( $M$ values ranged from i $8 \cdot 4$ to $7 \mathrm{I} \cdot 3 \%$ ) with respect to subject provision for all but one of the children (Gail $X^{2}=6 \cdot 46$, $d f=2, p<0.05$; non-significant $X^{2}$ values ranged between 0.02 and 4.67 ).

Similar analyses were carried out to determine whether there were differences between the groups of verbs with respect to the children's levels of direct object provision with verbs that take obligatory direct object arguments. ${ }^{7}$ Mann-Whitney tests revealed that for the first measure of semantic generality, there were no differences in the levels of direct object provision between the semantically general ( $M$ values ranged from 55.4 to $100 \%$ ) and more specific verbs ( $M$ values ranged from $4 \mathrm{I} \cdot \mathrm{I}$ to $94 \cdot 6 \%$ ) (non-significant $z$ values ranged between $0 \cdot 2 \mathrm{I}$ and $\mathrm{I} \cdot 22$ ). For the second measure of semantic generality, Kruskal-Wallis tests showed that there were no differences between light ( $M$ values ranged from $48 \cdot 7$ to $96 \cdot 9 \%$ ), part-light ( $M$ values ranged from 66.7 to $100 \%$ ) and non-light verbs ( $M$ values ranged from I 6.7 to $93.8 \%$ ) with respect to direct object provision for all but one of the children ( $\operatorname{Liz} X^{2}=6 \cdot 17, d f=2, p<0.05$; non-significant $X^{2}$ values ranged between $0 \cdot 2 \mathrm{I}$ and $5 \cdot 3 \mathrm{I}$ ). This suggests that semantic generality plays only a very limited role in determining syntactic accuracy in children's speech.

\section{DISCUSSION}

The aim of the current study was to establish more precisely the relative influence of semantic generality and the properties of the input to which children are exposed on the early acquisition of verbs and their related argument structures in English. This question was addressed through the examination of longitudinal data from 9 English-speaking children who were just beginning to produce a range of different verbs in multiword

[7] Verbs were coded for obligatory transitivity according to Levin ( I 993). However, a small number of verbs can only be used without a direct object argument in structures that are unlikely to be found in children's early speech (e.g. cover as an imperative in cover for 30 minutes, build in the passive It was built in 30 days) so were included in the analysis. For the verb get, only uses denoting obtaining an object (not uses denoting getting up, down etc.) were included. 
utterances. The children's data were examined to determine the age at which particular verbs were acquired both overall and in specific syntactic structures and, in their Stage I data, the range of argument structures produced with individual verbs, the proportional use of particular verbs as a function of total verb use, and the extent to which children's early verb uses were grammatically accurate. For each measure of early verb use, the extent to which the semantic generality of individual verbs and/or the pattern of use of those verbs in the input predicted use in the children's speech was examined.

The first analysis examined the prediction, derived from Bloom's, Clark's, and Ninio's theories, that semantically general verbs should be acquired earlier than more specific verbs both overall (Clark) and in specific constructions (Bloom, Ninio). The data show that although both measures of semantic generality and frequency of verb use in the input are significantly correlated with age of acquisition of individual verbs for most of the children, once the effects of input frequency are removed, semantic generality plays a relatively minor role in determining the age of acquisition of verbs in the children's speech. This is true of both overall measures of the age of acquisition of individual verbs, and, more importantly, measures that examine the age of acquisition of individual verbs in the VO, SVO and intransitive constructions. This finding is particularly problematic for Ninio's account of early verb learning, as she claims that children can only acquire a range of specific verbs in a given syntactic structure after they have learned the structure through the use of semantically general verbs. Similarly, Bloom (I99I) suggests that new syntactic structures are first acquired with semantically general verbs before more specific verbs can be acquired in the structure in question. The current findings suggest that rather than children's early verb learning depending on the semantic generality of the verbs in question in a way that specifically aids early verb learning, children are learning verbs they hear in the input as a function of their relative frequency.

The second analysis examined the prediction, derived from Clark's, Ninio's and Pinker's theories, that semantically general verbs will show greater syntactic diversity than more specific verbs. The data show that there is no difference between semantically general and more specific verbs in their syntactic diversity. This finding is problematic for Clark's theory because it suggests that the children are not using semantically general verbs in place of more specific verbs they have not yet acquired. It is also problematic for Pinker's and Ninio's theories. Both theorists assume that semantically general verbs map more directly onto abstract representations of syntactic structure than more specific verbs, and that more specific verbs can only be acquired or properly mapped onto these representations once semantically general verbs have been mapped. The current findings suggest 
that the children are not more productive in their use of semantically general verbs than in their use of more specific verbs, raising questions as to exactly what benefit the children gain from the closer syntax-semantics correspondences for semantically general verbs.

The third analysis tested Clark's prediction that semantically general verbs constitute a higher proportion of children's early verb use than at later stages by comparing the proportional use of semantically general verbs in the children's speech and in the input. The results show that there is no difference in the proportional use of semantically general verbs in the children's speech and in the input. This suggests that the children are not using semantically general verbs in place of more specific verbs that they have not yet acquired. Instead, their relative frequency of use mirrors the relative frequency of use in the input.

The final analysis examined the prediction, derived from Ninio's and Pinker's theories, that semantically general verbs should be used with greater syntactic accuracy than more specific verbs. This prediction was tested with respect to the children's use of subject and direct object arguments in obligatory contexts. The findings show that there is no difference between semantically general and more specific verbs in the syntactic accuracy of the children's utterances. This is problematic for Ninio's theory because it suggests that even at the very earliest stages of development, semantically general verbs are not more tightly linked than more specific verbs to the schemas that she assumes support the acquisition of more specific verbs in a given construction. This finding is also problematic for Pinker's theory because he suggests that only once children have acquired semantically general verbs will they be able to establish the precise semantics and therefore syntax of more specific verbs. If this were the case, semantically general verbs should be the first to make use of innate syntactic structure, and therefore should be produced with their obligatory arguments more often than more specific verbs.

In summary, the current findings put into question the idea that semantically general verbs are privileged in the early acquisition process and that they provide a route into argument structure. Overall there do not appear to be simple semantic criteria that differentiate between verbs to influence children's early verb use. However, although semantic generality does not appear to play a major role in determining children's early verb use, the data suggest it may play a role in some aspects of early verb learning for some children. To gain a fuller understanding of why this might be the case, a detailed examination of the precise semantic and pragmatic contexts in which individual verbs are produced is required that is not possible with the current data.

The claim that semantic generality does not play a major role in determining children's early verb use fits more comfortably with the cross-linguistic 
literature on early verb learning and the role of universal cognitive biases in development. Researchers report that in many languages, for example Tzeltal (Brown, I998a,b), Tzotzil (de Leon, I999), and Korean (Choi \& Bowerman, I99I), many of the first verbs acquired by children are semantically specific and Tzeltal-speaking children, at least, do not rely on semantically general verbs to a greater extent than adult speakers which would be expected if these verbs played a privileged role in the acquisition process (Brown, I 998a). The cross-linguistic evidence, combined with the findings of the current study, suggest that it is the frequency of individual verbs and their patterns of use in the input for the specific language children are learning rather than universal patterns of cognitive development that motivates early verb learning.

Although we are arguing that the semantic status of verbs does not play a significant role in determining children's early verb use, clearly, there is a role for semantics in language acquisition. First, it is widely acknowledged that verbs with similar meanings share strong similarities in the syntactic structures in which they may appear (e.g. Levin, I993). In our view, this means that semantics is likely to be important in the later development of more abstract constructions, and in determining the extent to which children generalize across verbs with similar meanings in terms of their use of argument structure constructions (see e.g. Diessel \& Tomasello, 200I). Second, there is some evidence that the narrow semantic verb classes that Pinker claims govern verb use have some psychological reality. Brooks \& Tomasello (i 999 ) taught children nonce verbs that belonged to semantic classes of fixed transitivity (inherently directed motion classes) and tried to elicit overgeneralization errors. Children aged $4 ; 6$ avoided using these verbs bitransitively showing their sensitivity to their semantic class whereas younger children made more errors. Crucially, this evidence in support of distinctions based on narrow range semantic criteria suggests that only from around age $4 ; 6$ are children able to make use of such complex criteria in their use of novel verbs. Third, the suggestion that semantics may play an important role in the generation of verb argument structures only during the later stages of development is supported by the fact that Englishspeaking children only begin to make verb argument structure overgeneralizations relatively late in development following a period of correct verb use (there are very few errors prior to age $3 ; 0$ ) and that such errors often involve semantically general verbs (Menyuk, I 969; Bowerman, I982). This suggests that only at this late stage in development do children begin to work out the particular components of verb meaning that govern adultlike use of argument structure. It is thus an empirical question whether, later in development, semantically general verbs play a central role in the abstraction of linguistic constructions that allow adultlike productivity with verb argument structure as suggested by Goldberg ( I 998, I 999). 
The original motivation behind semantic theories of verb acquisition was to provide children with a means to acquire or access abstract argument structure representations that would then support generalization of syntactic knowledge across verbs. If, as we suggest, the semantic status of individual verbs does not provide children with an early route into syntax, the question then is how do children begin to build more abstract representations of argument structure that allow them to generalize across verbs? A number of suggestions appear in the literature.

For English, word order and the slot-and-frame appearance of many constructions seem central to children's developing argument structure representations. Akhtar (I999) showed that younger children (two- and three-year-olds) were much less likely than older children (four-year-olds) to correct ungrammatical word order in transitive structures with novel verbs, and suggested that children need to acquire a number of exemplars of a given construction before they are able to abstract a more general schema that allows productivity with novel verbs (see also Abbot-Smith, Lieven \& Tomasello, 200I). Childers \& Tomasello (200I) found that children at 2;6 were able to generalize use of the transitive construction more readily when they were trained on transitive sentences where the subject and object arguments remained constant through the use of pronouns than when they were varied through the use of full NPs. They suggested that high frequency lexical items used in fixed sentence positions provide an organizational focus for children's developing knowledge of argument structure (see also Braine, I976; Lieven, Pine \& Baldwin, I997). Other suggestions include children attending to the number of arguments associated with individual verbs (Howe, 2002), and in languages where word order is much less stable, other grammatical markers may provide a route into syntax, for example, aspectual markers in Tzeltal (Brown, I998 $a, b$ ). Which particular units in a given language, and which particular distributions of these units will provide a basis for points of organization in children's developing grammars are likely to be determined by the frequency and distribution of particular units in the language children hear. These studies all point to a more drawn out pattern of acquisition, where children must recognize regularities in the distribution of particular lexical forms to begin to build more abstract representations of verb argument structure.

One possible objection to the current study might be that the way in which verbs were categorized according to semantic status might not be a true reflection of semantic generality, and may mask semantic effects. Most of the verbs produced early in development by young English-speaking children are relatively semantically transparent and therefore, it may be unrealistic to label some of these verbs as semantically more specific than others. However, increasing the range of verbs that are assumed to belong to the class of semantically general verbs results in a decrease in the 
predictive power of theories of acquisition that rely on semantic generality as a route into syntax. For example, if a wide range of different verbs are assumed to be semantically privileged, then it becomes increasingly difficult to predict which particular verbs will act as the 'pathbreakers' for syntactic development. If, to determine which of a wide range of possible verbs will lead children into syntax, researchers are forced to resort to predictions based on the frequency of use of individual verbs in the input, it is unclear what role semantic generality plays over and above the effects of input frequency.

Although we suggest that the input probably plays a more important role in the acquisition of language than is often assumed, it is clear that identifying relations between properties of the input, for example, frequency, and the language children produce, is not the whole story. To acquire some aspects of the linguistic system, children clearly need to do more than reproduce the input they hear, for example in learning how to reverse the use of personal pronouns (Oshima-Takane, I988). Much more research is needed to identify which specific aspects of the input are important in the acquisition process, both for English and across other languages. However, by starting from an accurate representation of the language children actually hear (e.g. Theakston et al., 200I), we are better able to develop psychologically realistic theories of early verb acquisition.

\section{REFERENCES}

Abbot-Smith, K., Lieven, E. V. M. \& Tomasello, M. (200I). What children do and do not do with ungrammatical word orders. Cognitive Development I6, I-I4.

Akhtar, N. (I999). Acquiring basic word order: evidence for data-driven learning of syntactic structure. Fournal of Child Language 26, 339-56.

Blewitt, P. (1982). Word meaning acquisition in young children: a review of theory and research. In H. W. Reese (ed.), Advances in child development and behavior 17, New York: Academic Press.

Bloom, L. (1991). Language development from two to three. Cambridge: CUP.

Bloom, L., Miller, P. \& Hood, L. (I975). Variation and reduction as aspects of competence in language development. In A. Pick (ed.), Minnesota symposia on child psychology, vol. 9. Minneapolis: University of Minnesota.

Bloom, L., Merkin, S. \& Wootten, J. (1982). Wh-questions: linguistic factors that contribute to the sequence of acquisition. Child Development 53, ro84-92.

Bowerman, M. (1982). Starting to talk worse: clues to language acquisition from children's late speech errors. In S. Strauss (ed.), U-shaped behavioral growth. New York: Academic Press.

Braine, M. D. S. (1976). Children's first word combinations. Monographs of the Society for Research in Child Development 4r (I, Serial No. I64).

Brooks, P. \& Tomasello, M. (I999). How children constrain their argument structure constructions. Language $\mathbf{7 5}, 720-38$.

Brown, P. (1998a). Children's first verbs in Tzeltal: evidence for an early verb category. Linguistics 36, 7 $13-53$.

Brown, P. (I $998 b$ ). Early Tzeltal verbs: argument structure and argument representation. In E. V. Clark (ed.), The proceedings of the twenty-ninth annual child language research forum. Stanford: Stanford Linguistics Society. 
Bybee, J., Perkins, R. \& Pagliuca, W. (1994). The evolution of grammar. Chicago: The University of Chicago Press.

Childers, J. \& Tomasello, M. (200I). The role of pronouns in young children's acquisition of the English transitive construction. Developmental Psychology 37, 739-48.

Choi, S. \& Bowerman, M. (I99I). Learning to express motion events in English and Korean: the influence of language-specific lexicalization patterns. Cognition 4I, 83-I2I.

Clark, E. V. (1978). Discovering what words can do. In D. Farkas, W. M. Jacobsen \& K. W. Todrys (eds), Papers from the Paracession on the Lexicon, Chicago Linguistics Society April I4-I 5, I978. Chicago : Chicago Linguistic Society, University of Chicago.

de Leon, L. (I 999). Verbs in Tzotzil (Mayan) early syntactic development. International Fournal of Bilingualism 3, 219-39.

de Villiers, J. (I984). Learning how to use verbs: lexical coding and the influence of the input. Fournal of Child Language 12, 587-95.

Diessel, H. \& Tomasello, M. (200I). The acquisition of finite complement clauses in English: a corpus-based analysis. Cognitive Linguistics I2, 97-I4I.

Foley, W. A. \& Olson, M. (1985). Clausehood and verb serialization. In J. Nichols \& A. C. Woodbury (eds), Grammar inside and outside the clause. Cambridge: CUP.

Forner, M. (I979). The mother as LAD: interaction between order and frequency of parental input and child production. In F. R. Eckman \& A. J. Hastings (eds), Studies in first and second language acquisition. Rowley, MA: Newbury House Publishers.

Goldberg, A. E. (1998). Patterns of experience in patterns of language. In M. Tomasello (ed.), The new psychology of language. Mahwah, NJ : Erlbaum.

Goldberg, A. E. (I 999). The emergence of the semantics of argument structure constructions. In B. MacWhinney (ed.), The emergence of language. Mahwah, NJ : Erlbaum.

Hollebrandse, B. \& van Hout, A. (1998). Aspectual bootstrapping via light verbs. In N. Dittmar \& Z. Penner (eds), Issues in the theory of language acquisition. Bern: Peter Lang.

Howe, C. (2002). The countering of overgeneralization. Fournal of Child Language 29, $875-95$.

Huttenlocher, J., Haight, W., Bryk, A., Seltzer, M. \& Lyons, T. (I99I). Early vocabulary growth: relation to language input and gender. Developmental Psychology 27, 236-48.

Levin, B. (1 993). English verb classes and alternations. Chicago: University of Chicago Press.

Lieven, E. V. M., Pine, J. M. \& Baldwin, G. (I997). Lexically-based learning and early grammatical development. Fournal of Child Language 24, I87-2 I9.

MacWhinney, B. (1995). The CHILDES project: tools for analyzing talk. Hillsdale, NJ: Erlbaum.

Menyuk, P. (1969). Sentences children use. Cambridge, MA: MIT Press.

Naigles, L. R. \& Hoff-Ginsberg, E. (I 998). Why are some verbs learned before other verbs? Effects of input frequency and structure on children's early verb use. Fournal of Child Language 25, 95-120.

Ninio, A. ( 1999 ). Model learning in syntactic development: intransitive verbs. International fournal of Bilingualism 3, I I I-3 I.

Ninio, A. (I999b). Pathbreaking verbs in syntactic development and the question of prototypical transitivity. Fournal of Child Language 26, 6 1 9-53.

Ninio, A. \& Keren-Portnoy, T. (2002). Mastering the syntax of pathbreaking verbs delays learning others of the same kind. Paper presented at the gth International Congress for the Study of Child Language and the Symposium on Research in Child Language Disorders, Madison, WI, July 2002.

Oshima-Takane, Y. (1988). Children learn from speech not addressed to them: the case of personal pronouns. Fournal of Child Language 15, 95-108.

Pinker, S. (1989). Learnability and cognition: the acquisition of verb-argument structure. Cambridge, MA: Harvard University Press.

Rowland, C. (2000). The grammatical acquisition of wh-questions in early English multi-word speech. Unpublished doctoral dissertation, University of Nottingham.

Stromswold, K. (1988). Linguistic representations of children's wh-questions. Papers and Reports of Child Language 27, I07-I4. 
Theakston, A. L., Lieven, E. V. M., Pine, J. M. \& Rowland, C. F. (200I). The role of performance relations in the acquisition of verb-argument structure: an alternative account. Fournal of Child Language $\mathbf{2 8}$ i 27-52.

Tomasello, M. (1992). First verbs : a case study of early grammatical development. Cambridge: CUP.

Traugott, E. C. \& Heine, B. (eds) (I99I). Approaches to grammaticalization, vol. I. Amsterdam: Benjamins.

\section{APPENDIX I}

VERBS PRODUCED BY INDIVIDUAL CHILDREN AND SEMANTIC CATEGORIZATION SCHEME

\begin{tabular}{|c|c|c|c|}
\hline & $\mathrm{T}$ & $\begin{array}{l}\text { Semantic } \\
\text { scheme I }\end{array}$ & $\begin{array}{l}\text { Semantic } \\
\text { scheme } 2\end{array}$ \\
\hline Ask & & non_light & non_light \\
\hline Bang & & non_light & non_light \\
\hline Bark & & non_light & non_light \\
\hline Bash & & non_light & non_light \\
\hline Beep & & non_light & non_light \\
\hline Bite & & non_light & non_light \\
\hline Bless & $\mathrm{T}$ & non_light & non_light \\
\hline Blow & & non_light & non_light \\
\hline Bounce & & non_light & non_light \\
\hline Break & & non_light & non_light \\
\hline Bring & $\mathrm{T}$ & light & light \\
\hline Brush & & non_light & non_light \\
\hline Build & $\mathrm{T}$ & non_light & light \\
\hline Bump & & non_light & non_light \\
\hline Buy & $\mathrm{T}$ & non_light & non_light \\
\hline Carry & $\mathrm{T}$ & non_light & part_light \\
\hline Catch & & non_light & non_light \\
\hline Change & & non_light & non_light \\
\hline Chase & & non_light & non_light \\
\hline Cheat & & non_light & non_light \\
\hline Check & & non_light & non_light \\
\hline Chew & & non_light & non_light \\
\hline Chuck & $\mathrm{T}$ & non_light & non_light \\
\hline Clap & & non_light & non_light \\
\hline Clean & & non_light & non_light \\
\hline Click & & non_light & non_light \\
\hline Climb & & non_light & non_light \\
\hline Clip & & non_light & non_light \\
\hline Colour & & non_light & non_light \\
\hline Comb & $\mathrm{T}$ & non_light & non_light \\
\hline Come & & light & light \\
\hline Cook & & non_light & non_light \\
\hline Cough & & non_light & non_light \\
\hline Count & & non_light & non_light \\
\hline Cover & $\mathrm{T}$ & non_light & non_light \\
\hline Crash & & non_light & non_light \\
\hline Crawl & & non_light & non_light \\
\hline
\end{tabular}


THEAKSTON ETAL.

APPENDIX I (Cont.)

\begin{tabular}{|c|c|c|c|}
\hline & $\mathrm{T}$ & $\begin{array}{l}\text { Semantic } \\
\text { scheme I }\end{array}$ & $\begin{array}{l}\text { Semantic } \\
\text { scheme } 2\end{array}$ \\
\hline Crayon & & non_light & non_light \\
\hline Cry & & non_light & non_light \\
\hline Cuddle & & non_light & non_light \\
\hline Cut & & non_light & non_light \\
\hline Dance & & non_light & non_light \\
\hline Do & $\mathrm{T}$ & light & light \\
\hline Draw & & non_light & light \\
\hline Dress & & non_light & non_light \\
\hline Dribble & & non_light & non_light \\
\hline Drink & & non_light & light \\
\hline Drive & & non_light & non_light \\
\hline Drop & & non_light & non_light \\
\hline Dry & & non_light & non_light \\
\hline Dunk & & non_light & non_light \\
\hline Eat & & non_light & light \\
\hline Fall & & non_light & light \\
\hline Fasten & & non_light & non_light \\
\hline Feed & $\mathrm{T}$ & non_light & non_light \\
\hline Feel & & non_light & non_light \\
\hline Fetch & $\mathrm{T}$ & non_light & non_light \\
\hline Fight & & non_light & non_light \\
\hline Find & $\mathrm{T}$ & non_light & light \\
\hline Finish & & non_light & part_light \\
\hline Fish & & non_light & non_light \\
\hline Fit & & non_light & non_light \\
\hline Fix & $\mathrm{T}$ & non_light & non_light \\
\hline Fly & & non_light & non_light \\
\hline Forget & & non_light & non_light \\
\hline Get & $\mathrm{T}$ & light & light \\
\hline Give & $\mathrm{T}$ & light & light \\
\hline Go & & light & light \\
\hline Happen & & non_light & non_light \\
\hline Have & $\mathrm{T}$ & non_light & light \\
\hline Hear & & non_light & light \\
\hline Help & & non_light & non_light \\
\hline Hide & & non_light & non_light \\
\hline Hit & & non_light & part_light \\
\hline Hold & $\mathrm{T}$ & non_light & light \\
\hline Hurt & & non_light & non_light \\
\hline Joke & & non_light & non_light \\
\hline Juggle & & non_light & non_light \\
\hline Jump & & non_light & non_light \\
\hline Keep & & non_light & non_light \\
\hline Kick & & non_light & non_light \\
\hline Kiss & & non_light & non_light \\
\hline Knock & & non_light & non_light \\
\hline Know & & non_light & part_light \\
\hline Land & & non_light & non_light \\
\hline Leave & & non_light & non_light \\
\hline Let & $\mathrm{T}$ & non_light & non_light \\
\hline
\end{tabular}


APPENDIX I (Cont.)

\begin{tabular}{|c|c|c|c|}
\hline & $\mathrm{T}$ & $\begin{array}{l}\text { Semantic } \\
\text { scheme I }\end{array}$ & $\begin{array}{l}\text { Semantic } \\
\text { scheme } 2\end{array}$ \\
\hline Lick & $\mathrm{T}$ & non_light & non_light \\
\hline Lie & & non_light & part_light \\
\hline Lift & $\mathrm{T}$ & non_light & non_light \\
\hline Like & $\mathrm{T}$ & non_light & part_light \\
\hline Listen & & non_light & non_light \\
\hline Look & & non_light & non_light \\
\hline Lose & $\mathrm{T}$ & non_light & non_light \\
\hline Make & $\mathrm{T}$ & light & light \\
\hline Mend & & non_light & non_light \\
\hline Mind & & non_light & non_light \\
\hline Miss & & non_light & non_light \\
\hline Move & & non_light & part_light \\
\hline Need & $\mathrm{T}$ & non_light & part_light \\
\hline Nip & & non_light & non_light \\
\hline Open & & non_light & non_light \\
\hline Pack & & non_light & non_light \\
\hline Paint & & non_light & non_light \\
\hline Park & & non_light & non_light \\
\hline Pass & & non_light & non_light \\
\hline Patter & & non_light & non_light \\
\hline Pay & & non_light & part_light \\
\hline Peck & & non_light & non_light \\
\hline Peel & $\mathrm{T}$ & non_light & non_light \\
\hline Peep & & non_light & non_light \\
\hline Pick & $\mathrm{T}$ & non_light & non_light \\
\hline Pinch & $\mathrm{T}$ & non_light & non_light \\
\hline Play & & non_light & part_light \\
\hline Poke & $\mathrm{T}$ & non_light & non_light \\
\hline Poo & & non_light & non_light \\
\hline Pop & & non_light & non_light \\
\hline Pour & & non_light & non_light \\
\hline Press & & non_light & non_light \\
\hline Pretend & & non_light & non_light \\
\hline Promise & & non_light & non_light \\
\hline Pull & & non_light & non_light \\
\hline Purr & & non_light & non_light \\
\hline Push & & non_light & non_light \\
\hline Put & $\mathrm{T}$ & light & light \\
\hline Rain & & non_light & non_light \\
\hline Reach & & non_light & non_light \\
\hline Read & & non_light & non_light \\
\hline Rest & & non_light & non_light \\
\hline Ride & & non_light & non_light \\
\hline Ring & & non_light & non_light \\
\hline Rip & & non_light & non_light \\
\hline Rock & & non_light & non_light \\
\hline Roll & & non_light & non_light \\
\hline Row & & non_light & non_light \\
\hline Rub & & non_light & non_light \\
\hline Run & & non_light & non_light \\
\hline
\end{tabular}


APPENDIX I (Cont.)

\begin{tabular}{|c|c|c|c|}
\hline & $\mathrm{T}$ & $\begin{array}{l}\text { Semantic } \\
\text { scheme I }\end{array}$ & $\begin{array}{l}\text { Semantic } \\
\text { scheme } 2\end{array}$ \\
\hline Say & & non_light & non_light \\
\hline Scratch & & non_light & non_light \\
\hline See & & non_light & light \\
\hline Share & & non_light & non_light \\
\hline Shop & & non_light & non_light \\
\hline Show & $\mathrm{T}$ & non_light & non_light \\
\hline Shut & & non_light & non_light \\
\hline Sing & & non_light & non_light \\
\hline Sit & & non_light & part_light \\
\hline Skate & & non_light & non_light \\
\hline Skip & & non_light & non_light \\
\hline Sleep & & non_light & part_light \\
\hline Slip & & non_light & non_light \\
\hline Smile & & non_light & non_light \\
\hline Sneeze & & non_light & non_light \\
\hline Snow & & non_light & non_light \\
\hline Spill & & non_light & non_light \\
\hline Splash & & non_light & non_light \\
\hline Stand & & non_light & part_light \\
\hline Start & & non_light & non_light \\
\hline Stick & & non_light & non_light \\
\hline Stir & $\mathrm{T}$ & non_light & non_light \\
\hline Stop & & non_light & part_light \\
\hline Stroke & $\mathrm{T}$ & non_light & non_light \\
\hline Sweep & & non_light & non_light \\
\hline Swim & & non_light & non_light \\
\hline Take & $\mathrm{T}$ & light & light \\
\hline Talk & & non_light & non_light \\
\hline Taste & $\mathrm{T}$ & non_light & non_light \\
\hline Tell & $\mathrm{T}$ & non_light & non_light \\
\hline Think & & non_light & non_light \\
\hline Throw & & non_light & part_light \\
\hline Tickle & $\mathrm{T}$ & non_light & non_light \\
\hline Tidy & & non_light & non_light \\
\hline Tie & $\mathrm{T}$ & non_light & non_light \\
\hline Tip & $\mathrm{T}$ & non_light & non_light \\
\hline Touch & & non_light & non_light \\
\hline Try & & non_light & non_light \\
\hline Tuck & $\mathrm{T}$ & non_light & non_light \\
\hline Turn & & non_light & non_light \\
\hline Twist & & non_light & non_light \\
\hline Understand & & non_light & non_light \\
\hline Use & $\mathrm{T}$ & non_light & non_light \\
\hline Wait & & non_light & part_light \\
\hline Wake & & non_light & non_light \\
\hline Walk & & non_light & part_light \\
\hline Want & $\mathrm{T}$ & non_light & light \\
\hline Wash & & non_light & non_light \\
\hline Watch & & non_light & non_light \\
\hline Water & $\mathrm{T}$ & non_light & non_light \\
\hline
\end{tabular}


LIGHT VERBS

APPENDIX I (Cont.)

\begin{tabular}{llll}
\hline & T & $\begin{array}{l}\text { Semantic } \\
\text { scheme I }\end{array}$ & $\begin{array}{l}\text { Semantic } \\
\text { scheme 2 }\end{array}$ \\
Wear & $\mathrm{T}$ & non_light & non_light \\
Wee & & non_light & non_light \\
Wiggle & & non_light & non_light \\
Win & & non_light & non_light \\
Wind & & non_light & non_light \\
Wipe & & non_light & non_light \\
Work & & non_light & non_light \\
Write & $\mathrm{T}$ & non_light & non_light \\
Zip & $\mathrm{T}$ &
\end{tabular}

$\mathrm{T}$ : marks transitive verbs coded for direct object provision. 